\title{
The hemorrhagic transformation index score: a prediction tool in middle cerebral artery ischemic stroke
}

Mikhail N. Kalinin ${ }^{1,2^{*}}$, Dina R. Khasanova ${ }^{1,2}$ and Murat M. Ibatullin ${ }^{1,3}$

\begin{abstract}
Background: We aimed to develop a tool, the hemorrhagic transformation $(H T)$ index $(H T I)$, to predict any $H T$ within 14 days after middle cerebral artery (MCA) stroke onset regardless of the intravenous recombinant tissue plasminogen activator (IV rtPA) use. That is especially important in the light of missing evidence-based data concerning the timing of anticoagulant resumption after stroke in patients with atrial fibrillation (AF).
\end{abstract}

Methods: We retrospectively analyzed 783 consecutive MCA stroke patients. Clinical and brain imaging data at admission were recorded. A follow-up period was 2 weeks after admission. The patients were divided into derivation (DC) and validation (VC) cohorts by generating Bernoulli variates with probability parameter 0.7 . Univariate/multivariate logistic regression, and factor analysis were used to extract independent predictors. Validation was performed with internal consistency reliability and receiver operating characteristic (ROC) analysis. Bootstrapping was used to reduce bias.

Results: The HTI was composed of 4 items: Alberta Stroke Program Early CT score (ASPECTS), National Institutes of Health Stroke Scale (NIHSS), hyperdense MCA (HMCA) sign, and AF on electrocardiogram (ECG) at admission. According to the predicted probability (PP) range, scores were allocated to ASPECTS as follows: $10-7=0 ; 6-5=1 ; 4-3=2 ; 2-0=3$; to NIHSS: 0-11 = 0; 12-17 = 1; 18-23=2; $>23=3$; to HMCA sign: yes $=1$; to AF on ECG: yes $=1$. The HTI score varied from 0 to 8 . For each score, adjusted PP of any HT with $95 \%$ confidence intervals (Cl) was as follows: $0=0.027(0.011-0.042)$; $1=0.07(0.043-0.098) ; 2=0.169(0.125-0.213) ; 3=0.346(0.275-0.417) ; 4=0.571(0.474-0.668) ; 5=0.768(0.676-0.861)$; $6=0.893(0.829-0.957) ; 7=0.956(0.92-0.992) ; 8=0.983(0.965-1.0)$. The optimal cutpoint score to differentiate between $\mathrm{HT}$-positive and negative groups was 2 (95\% normal-based $\mathrm{Cl}, 1-3$ ) for the DC and VC alike. ROC area/ sensitivity/specificity with 95\% normal-based Cl for the DC and VC were $0.85(0.82-0.89) / 0.82(0.73-0.9) / 0.89(0.8-0.97)$ and $0.83(0.78-0.88) / 0.8(0.66-0.94) / 0.87(0.73-1.0)$ respectively. McDonald's categorical omega with $95 \%$ bias-corrected and accelerated $\mathrm{Cl}$ for the DC and VC was $0.81(0.77-0.84)$ and $0.82(0.76-0.86)$ respectively.

Conclusions: The HTI is a simple yet reliable tool to predict any HT within 2 weeks after MCA stroke onset regardless of the IV rtPA use.

Keywords: Stroke, Middle cerebral artery, Complication, Hemorrhage, Prognosis, Hemorrhagic transformation

\footnotetext{
*Correspondence: ninilak@gmail.com

'Department of Neurology and Neurosurgery for Postgraduate Training,

Kazan State Medical University, Kazan, Russia

${ }^{2}$ Department of Neurology, Interregional Clinical Diagnostic Center, 12A

Karbyshev St, Kazan 420101, Russia

Full list of author information is available at the end of the article
} 
Table 1 Variables with Missing Values

\begin{tabular}{lll}
\hline & Missing, $n$ (\%) & Valid, $n$ \\
\hline Cholesterol, total & $107(13.7)$ & 676 \\
LVEF & $80(10.2)$ & 703 \\
AST & $61(7.8)$ & 722 \\
Bilirubin, total & $55(7)$ & 728 \\
Fibrinogen & $41(5.2)$ & 742 \\
Albumin & $37(4.7)$ & 746 \\
Protein, total & $18(2.3)$ & 765 \\
Sodium & $11(1.4)$ & 772 \\
Potassium & $10(1.3)$ & 773 \\
Prothrombin time & $5(0.6)$ & 778 \\
ALT & $4(0.5)$ & 779 \\
Urea & $2(0.3)$ & 781 \\
Hematocrit & $2(0.3)$ & 781 \\
Hemoglobin & $1(0.1)$ & 782 \\
\hline Note: ALT stands for Alanine transaminase, AST Aspartate transaminase, and \\
LVEF Left ventricular ejection fraction (echocardiography, Simpson method)
\end{tabular}

\section{Background}

Hemorrhagic transformation (HT), either asymptomatic (AHT) or symptomatic (SHT), is considered to be a notorious complication of acute ischemic stroke (AIS), associated with limited treatment options and long-term adverse outcomes [1]. It seems reasonable that efforts should be directed towards preventing HT before it occurs. Fortunately, it is more predictable than other types of intracranial hemorrhage.

In AIS patients, the incidence of HT induced by intravenous recombinant tissue plasminogen activator (IV rtPA) is reported to be $4.5-39.6 \%$ for AHT and $5.2-7.3 \%$ for SHT. In contrast, the rate of spontaneous AHT and SHT ranges from $13 \%$ to $43 \%$ and from $0.6 \%$ to $20 \%$ respectively [2, 3]. Although the proportion of AIS patients treated with IV rtPA is relatively small (4.7-21.4\%) [4], the majority of authors have focused on searching HT

Table 2 MI Specification

\begin{tabular}{ll}
\hline $\begin{array}{l}\text { Software package } \\
\text { Random number } \\
\text { generator }\end{array}$ & Mersenne twister \\
Imputation method & Fully conditional specification (MCMC) \\
Model type & Linear regression, no interaction terms \\
Number of iterations & 100 \\
Predictors & All collected data, including missing variables \\
Restrictions & Extrema of source data \\
Number of imputations & 15 \\
Quality of MI & No pattern on MCMC convergence charts \\
& FMI, RIV, RE (Table 4)
\end{tabular}

Note: FMI stands for Fraction of missing information, MCMC Markov chain Monte Carlo, RE Relative efficiency, and RIV Relative increase in variance
Table 3 Baseline Characteristics in the DC and VC

\begin{tabular}{|c|c|c|c|}
\hline & $\mathrm{DC}(n=535)$ & $\mathrm{VC}(n=248)$ & $\begin{array}{l}p- \\
\text { Value }\end{array}$ \\
\hline \multicolumn{4}{|l|}{ Clinical data, median (IQR) } \\
\hline Age $(y)$ & $71(60-78)$ & $69(61-77)$ & 0.924 \\
\hline $\mathrm{DBP}(\mathrm{mm} \mathrm{Hg})$ & $90(80-100)$ & $100(80-100)$ & 0.025 \\
\hline Height (m) & $1.65(1.6-1.72)$ & $1.65(1.58-1.71)$ & 0.063 \\
\hline Male sex, $n(\%)$ & $289(54)$ & $125(50.4)$ & 0.346 \\
\hline NIHSS & $8(4-16)$ & $8(4-16)$ & 0.574 \\
\hline Pulse rate (bpm) & $78(74-83)$ & $78(74-85)$ & 0.155 \\
\hline $\mathrm{SBP}(\mathrm{mm} \mathrm{Hg})$ & $160(140-180)$ & $160(140-180)$ & 0.19 \\
\hline Time from onset (h) & $5.5(2-11)$ & $6(2.5-11)$ & 0.265 \\
\hline Temperature $\left({ }^{\circ} \mathrm{C}\right)$ & $36.6(36.4-36.6)$ & $36.6(36.5-36.6)$ & 0.194 \\
\hline Weight (kg) & $78(68-88)$ & $76.7(68-85)$ & 0.476 \\
\hline \multicolumn{4}{|l|}{ Stroke cause, $n(\%)$} \\
\hline Large-artery atherosclerosis & $212(39.6)$ & $109(44)$ & 0.252 \\
\hline Cardioembolism & $225(42.1)$ & $101(40.7)$ & 0.725 \\
\hline Small-vessel occlusion & $79(14.8)$ & $33(13.3)$ & 0.587 \\
\hline Other determined etiology & $7(1.3)$ & $1(0.4)$ & 0.241 \\
\hline Undetermined etiology & $12(2.2)$ & $4(1.6)$ & 0.562 \\
\hline \multicolumn{4}{|l|}{ Risk factors, $n(\%)$} \\
\hline Acute myocardial infarction & $25(4.7)$ & $8(3.2)$ & 0.348 \\
\hline AF history & $210(39.3)$ & $94(37.9)$ & 0.719 \\
\hline Alcohol abuse & $62(11.6)$ & $29(11.7)$ & 0.966 \\
\hline Atherosclerosis & $528(98.7)$ & $248(100)$ & 0.07 \\
\hline Bleeding history & $41(7.7)$ & $27(10.9)$ & 0.136 \\
\hline Chronic heart failure & $62(11.6)$ & $28(11.3)$ & 0.903 \\
\hline Chronic liver failure & $5(0.9)$ & $7(2.8)$ & 0.045 \\
\hline Chronic renal failure & $20(3.7)$ & $11(4.4)$ & 0.642 \\
\hline Coronary artery disease & $191(35.7)$ & 89 (35.9) & 0.96 \\
\hline Diabetes mellitus & $142(26.5)$ & $69(27.8)$ & 0.707 \\
\hline Dyslipidemia & $216(40.4)$ & $103(41.5)$ & 0.759 \\
\hline Hypertension & $497(92.9)$ & $230(92.7)$ & 0.937 \\
\hline Malignancy & $10(1.9)$ & $4(1.6)$ & 0.801 \\
\hline Seizures at onset & $10(1.9)$ & $3(1.2)$ & 0.502 \\
\hline Previous TIA/stroke & $221(41.3)$ & $116(46.8)$ & 0.151 \\
\hline \multicolumn{4}{|l|}{ Brain CT, $n(\%)$} \\
\hline ASPECTS, median (IQR) & $8(6-9)$ & $8(6-9)$ & 0.708 \\
\hline HMCA sign & $141(26.4)$ & $66(26.6)$ & 0.939 \\
\hline Leukoaraiosis & $347(64.9)$ & $168(67.7)$ & 0.429 \\
\hline Left hemispheric stroke & $286(53.5)$ & $122(49.2)$ & 0.266 \\
\hline Right hemispheric stroke & $234(43.7)$ & $122(49.2)$ & 0.154 \\
\hline Bihemispheric stroke & $15(2.8)$ & $4(1.6)$ & 0.314 \\
\hline
\end{tabular}

Blood tests, median (IQR)

Albumin (g/L), $n=513 / 233$

$41.1(38.6-43.1) \quad 40.7(38.8-42.9) \quad 0.612$

$\operatorname{ALT}(I U / L), n=531 / 248$

$20(14-28)$

$19(13.2-29.8) \quad 0.48$ 
Table 3 Baseline Characteristics in the DC and VC (Continued)

\begin{tabular}{|c|c|c|c|}
\hline AST (IU/L), $n=495 / 227$ & $24(19-31)$ & $23(19-32)$ & 0.939 \\
\hline APTT (s) & $32(28.8-35.3)$ & $31.9(28.7-34.5)$ & 0.299 \\
\hline $\begin{array}{l}\text { Bilirubin, total }(\mu \mathrm{mol} / \mathrm{L}) \\
n=497 / 231\end{array}$ & $11.5(8.3-17)$ & $11.5(8-16.1)$ & 0.699 \\
\hline $\begin{array}{l}\text { Cholesterol, total (mmol/L), } \\
n=467 / 209\end{array}$ & $5.1(4.3-5.9)$ & $5.2(4.3-6.1)$ & 0.286 \\
\hline Creatinine $(\mu \mathrm{mol} / \mathrm{L})$ & $90.6(79.3-106)$ & $90(77.4-108)$ & 0.851 \\
\hline $\begin{array}{l}\text { Fibrinogen }(g / L) \\
n=502 / 240\end{array}$ & $3.2(2.6-4)$ & $3.2(2.6-4.2)$ & 0.985 \\
\hline Glucose (mmol/L) & $6.8(5.9-8.3)$ & $6.8(5.9-8.1)$ & 0.998 \\
\hline Hematocrit, $n=534 / 247$ & $0.43(0.38-0.46)$ & $0.42(0.37-0.45)$ & 0.08 \\
\hline $\begin{array}{l}\text { Hemoglobin }(g / L) \\
n=535 / 247\end{array}$ & $141(128-153)$ & $139(124-150)$ & 0.12 \\
\hline INR & $1.04(0.96-1.15)$ & $1.05(0.98-1.15)$ & 0.361 \\
\hline Platelet count $\left(\times 10^{9}\right.$ cells/L) & $245(199-306)$ & $\begin{array}{l}249.5(201- \\
301)\end{array}$ & 0.865 \\
\hline $\begin{array}{l}\text { Protein, total }(\mathrm{g} / \mathrm{L}) \\
n=523 / 242\end{array}$ & $67.9(64.4-71.7)$ & $68.4(64.7-72.7)$ & 0.159 \\
\hline $\begin{array}{l}\text { Potassium (mmol/L), } \\
n=530 / 243\end{array}$ & $4(3.7-4.3)$ & $4(3.7-4.3)$ & 0.223 \\
\hline PT (s), $n=531 / 247$ & $12(10.9-14.8)$ & $12(11.2-15.3)$ & 0.408 \\
\hline $\mathrm{RBC}\left(\times 10^{12}\right.$ cells $\left./ \mathrm{L}\right)$ & $4.63(4.28-4.97)$ & $4.55(4.14-4.93)$ & 0.032 \\
\hline $\begin{array}{l}\text { Sodium }(\mathrm{mmol} / \mathrm{L}) \\
n=530 / 242\end{array}$ & $\begin{array}{l}139.5(138- \\
141.3)\end{array}$ & $\begin{array}{l}139.1(137- \\
141)\end{array}$ & 0.164 \\
\hline Urea $(\mathrm{mmol} / \mathrm{L}), n=533 / 248$ & $6(4.7-7.7)$ & $5.7(4.6-7.6)$ & 0.403 \\
\hline WBC $\left(\times 10^{9}\right.$ cells/L $)$ & $7.9(6.5-9.7)$ & $7.6(6.3-9.5)$ & 0.285 \\
\hline \multicolumn{4}{|l|}{$\mathrm{ECG}, n(\%)$} \\
\hline AF rhythm & $164(30.7)$ & $77(31)$ & 0.911 \\
\hline HR (bpm), median (IQR) & 79 (67-91) & $80(68-96)$ & 0.157 \\
\hline Normal ECG & $26(4.9)$ & $10(4)$ & 0.607 \\
\hline Other ECG changes & $259(48.4)$ & $121(48.8)$ & 0.921 \\
\hline $\begin{array}{l}\text { LVEF (\%), } n=486 / 217 \\
\text { median (IQR) }\end{array}$ & $57(50-60)$ & $57(50-61)$ & 0.993 \\
\hline \multicolumn{4}{|l|}{ Chest X-ray, n (\%) } \\
\hline Aortic atherosclerosis & $462(86.4)$ & $217(87.5)$ & 0.661 \\
\hline Cardiomegaly & $401(75)$ & $207(83.5)$ & 0.008 \\
\hline Normal chest X-ray & $28(5.2)$ & $13(5.2)$ & 0.996 \\
\hline Pleural effusion & $62(11.6)$ & $20(8.1)$ & 0.134 \\
\hline Pneumonia & $48(9)$ & $23(9.3)$ & 0.891 \\
\hline Pulmonary congestion & $215(40.2)$ & $109(44)$ & 0.32 \\
\hline \multicolumn{4}{|l|}{ Antithrombotic medication, $n(\%)$} \\
\hline Anticoagulant & $28(5.2)$ & $14(5.6)$ & 0.812 \\
\hline Antiplatelet & $390(73)$ & $201(81)$ & 0.014 \\
\hline Anticoagulant + antiplatelet & $66(12.3)$ & $17(6.9)$ & 0.02 \\
\hline IV rtPA & $51(9.5)$ & $16(6.5)$ & 0.152 \\
\hline \multicolumn{4}{|l|}{ Outcome, $n(\%)$} \\
\hline Any HT & $126(23.6)$ & $60(24.2)$ & 0.844 \\
\hline SHT & 69 (12.9) & $29(11.7)$ & 0.636 \\
\hline
\end{tabular}

Table 3 Baseline Characteristics in the DC and VC (Continued)

\begin{tabular}{llll}
\hline $\mathrm{HI}-1$ & $22(4.1)$ & $4(1.6)$ & 0.069 \\
$\mathrm{HI}-2$ & $82(15.3)$ & $38(15.3)$ & 0.999 \\
$\mathrm{PH}-1$ & $9(1.7)$ & $4(1.6)$ & 0.944 \\
$\mathrm{PH}-2$ & $13(2.4)$ & $14(5.6)$ & 0.022 \\
Death & $34(6.4)$ & $19(7.7)$ & 0.499 \\
Malignant cerebral edema & $32(6)$ & $14(5.6)$ & 0.852 \\
Dependency & $325(60.7)$ & $147(59.3)$ & 0.695 \\
\hline
\end{tabular}

Note: $A P T T$ stands for Activated partial thromboplastin time, DBP Diastolic blood pressure, INR International normalized ratio, $P T$ Prothrombin time, $R B C$ Red blood cells, SBP Systolic blood pressure, and WBC White blood cells

predictors coupled with IV rtPA over the past decade. As a result, a variety of predictive clinical scores have emerged [5-9].

On the other hand, there is a lack of tools for making an accurate HT prediction in AIS patients who are not eligible for IV rtPA. That is especially important in the light of missing evidence-based data concerning the timing of anticoagulant resumption after AIS in patients with atrial fibrillation (AF). Recommendations on the initiation of anticoagulation are currently based on consensus opinion, in what is known as the "1-3-6-12 day rule" [10]. Therefore, the two-week timeframe following the AIS onset is the most critical for developing HT. In this instance, an accurate prediction of HT could make a difference in decision making to reinstitute anticoagulation. The middle cerebral artery (MCA) is by far the largest cerebral artery and is the vessel most commonly affected by cerebrovascular accident.

Given the background, we aimed to develop a simple and yet reliable instrument called the hemorrhagic transformation index (HTI) to predict any HT within 14 days after AIS onset in the MCA territory regardless of the use of IV rtPA.

\section{Methods \\ Patients}

Using prospectively collected clinical and radiological databases, we retrospectively identified 783 consecutive patients with AIS in the MCA territory who were admitted to the stroke unit of the Interregional Clinical Diagnostic Center, Kazan, Russia, within $12 \mathrm{~h}$ after onset between January 2013 and May 2016. The exclusion criteria were: involvement of other vascular territories; AIS following any surgery or endovascular procedure within 1 month; brain ischemic lesions due to an intracranial tumor, infection, cerebral venous thrombosis, subarachnoid hemorrhage, and arteriovenous malformation/fistula. In total, 1361 AIS patients were admitted over the specified period. The sample was drawn from the local Caucasian population. 
Table 4 Univariate Analysis in the DC Using the MI Dataset

\begin{tabular}{|c|c|c|c|c|c|c|c|}
\hline & Any HT $(n=126)$ & No HT $(n=409)$ & OR $(95 \% \mathrm{Cl})$ & $p$-Value & FMl & RIV & $\mathrm{RE}$ \\
\hline \multicolumn{8}{|l|}{ Clinical data, median (IQR) } \\
\hline Age $(y)$ & $74(62-79)$ & $70(60-77)$ & $1.016(0.998-1.034)$ & 0.077 & 0 & 0 & 1 \\
\hline $\mathrm{DBP}(\mathrm{mm} \mathrm{Hg})$ & $90(80-100)$ & $90(80-100)$ & $0.992(0.979-1.005)$ & 0.217 & 0 & 0 & 1 \\
\hline Height (m) & $1.65(1.6-1.7)$ & $1.66(1.6-1.73)$ & $0.983(0.961-1.006)$ & 0.138 & 0 & 0 & 1 \\
\hline Male sex, $n(\%)$ & $60(47.6)$ & $229(56)$ & $0.715(0.479-1.066)$ & 0.1 & 0 & 0 & 1 \\
\hline NIHSS & $20(14-23)$ & $6(3-10)$ & $1.253(1.206-1.302)$ & $<0.001$ & 0 & 0 & 1 \\
\hline Pulse rate (bpm) & $80(74-88)$ & $78(72-80)$ & $1.037(1.021-1.053)$ & $<0.001$ & 0 & 0 & 1 \\
\hline $\mathrm{SBP}(\mathrm{mm} \mathrm{Hg})$ & $155(140-180)$ & $160(140-179)$ & $0.999(0.992-1.006)$ & 0.683 & 0 & 0 & 1 \\
\hline Temperature $\left({ }^{\circ} \mathrm{C}\right)$ & $36.6(36.4-36.7)$ & $36.6(36.4-36.6)$ & $1.658(0.904-3.041)$ & 0.102 & 0 & 0 & 1 \\
\hline Weight (kg) & $76(65-90)$ & $79.5(70-87)$ & $0.998(0.986-1.01)$ & 0.759 & 0 & 0 & 1 \\
\hline \multicolumn{8}{|l|}{ Risk factors, $n(\%)$} \\
\hline Acute myocardial infarction & $16(12.6)$ & $9(2.2)$ & $6.39(2.75-14.851)$ & $<0.001$ & 0 & 0 & 1 \\
\hline AF history & $81(63.8)$ & $129(31.6)$ & $3.808(2.508-5.783)$ & $<0.001$ & 0 & 0 & 1 \\
\hline Alcohol abuse & $11(8.7)$ & $51(12.5)$ & $0.664(0.335-1.316)$ & 0.241 & 0 & 0 & 1 \\
\hline Atherosclerosis & $124(97.6)$ & 404 (99) & 0.409 (0.09-1.853) & 0.246 & 0 & 0 & 1 \\
\hline Bleeding history & $9(7.1)$ & $32(7.8)$ & $1.116(0.518-2.405)$ & 0.78 & 0 & 0 & 1 \\
\hline Chronic heart failure & $24(18.4)$ & $38(9.3)$ & $0.441(0.253-0.768)$ & 0.004 & 0 & 0 & 1 \\
\hline Chronic liver failure & $1(0.8)$ & $4(1)$ & $0.802(0.89-7.237)$ & 0.844 & 0 & 0 & 1 \\
\hline Chronic renal failure & $7(5.5)$ & $13(3.2)$ & $1.772(0.691-4.543)$ & 0.233 & 0 & 0 & 1 \\
\hline Coronary artery disease & $56(44.1)$ & $135(33.1)$ & $1.595(1.062-2.395)$ & 0.024 & 0 & 0 & 1 \\
\hline Diabetes mellitus & $39(30.7)$ & $103(25.2)$ & $1.312(0.847-2.034)$ & 0.224 & 0 & 0 & 1 \\
\hline Dyslipidemia & $41(32.3)$ & $175(42.9)$ & $0.635(0.417-0.967)$ & 0.034 & 0 & 0 & 1 \\
\hline Hypertension & $118(92.9)$ & $379(92.9)$ & $0.997(0.459-2.166)$ & 0.994 & 0 & 0 & 1 \\
\hline Malignancy & $4(3.1)$ & $6(1.5)$ & $2.179(0.605-7.846)$ & 0.233 & 0 & 0 & 1 \\
\hline Previous TIA/stroke & $51(40.2)$ & $170(41.7)$ & $0.939(0.626-1.41)$ & 0.763 & 0 & 0 & 1 \\
\hline Seizures at onset & $0(0)$ & $10(2.5)$ & - & $0.075^{\mathrm{a}}$ & 0 & 0 & 1 \\
\hline \multicolumn{8}{|l|}{ Brain $C T, n(\%)$} \\
\hline ASPECTS, median (IQR) & $4(1-6)$ & $8(7-9)$ & $0.499(0.44-0.567)$ & $<0.001$ & 0 & 0 & 1 \\
\hline HMCA sign & $88(69.3)$ & $54(13.2)$ & 14.792 (9.213-23.749) & $<0.001$ & 0 & 0 & 1 \\
\hline Leukoaraiosis & $87(68.5)$ & $260(63.7)$ & $1.238(0.809-1.894)$ & 0.325 & 0 & 0 & 1 \\
\hline Left hemispheric stroke & $73(58)$ & $213(52)$ & $1.291(0.863-1.931)$ & 0.214 & 0 & 0 & 1 \\
\hline Right hemispheric stroke & $53(42)$ & $181(44.3)$ & $0.898(0.6-1.344)$ & 0.602 & 0 & 0 & 1 \\
\hline Bihemispheric stroke & $0(0)$ & $15(3.7)$ & - & $0.028^{\mathrm{a}}$ & 0 & 0 & 1 \\
\hline \multicolumn{8}{|l|}{ Stroke cause, $n(\%)$} \\
\hline Large-artery atherosclerosis & $41(32.5)$ & $171(41.8)$ & $0.671(0.441-1.023)$ & 0.064 & 0 & 0 & 1 \\
\hline Cardioembolism & $79(62.7)$ & $146(35.7)$ & $3.028(2.002-4.58)$ & $<0.001$ & 0 & 0 & 1 \\
\hline Small-vessel occlusion & $0(0)$ & $79(19.3)$ & - & $<0.001^{\mathrm{a}}$ & 0 & 0 & 1 \\
\hline Other determined etiology & $1(0.8)$ & $6(1.5)$ & $0.537(0.064-4.506)$ & 0.567 & 0 & 0 & 1 \\
\hline Undetermined etiology & $5(4)$ & $7(1.7)$ & $2.373(0.74-7.612)$ & 0.146 & 0 & 0 & 1 \\
\hline $\operatorname{LVEF}(\%), n=120 / 366$, median (IQR) & $55(46.25-59)$ & $58(53-61.25)$ & $0.957(0.938-0.975)$ & $<0.001$ & 0.026 & 0.027 & 0.998 \\
\hline \multicolumn{8}{|l|}{ Chest X-ray, n (\%) } \\
\hline Aortic atherosclerosis & $114(89.8)$ & $348(85.3)$ & $1.512(0.801-2.85)$ & 0.203 & 0 & 0 & 1 \\
\hline Cardiomegaly & $109(85.8)$ & $292(71.6)$ & $2.406(1.398-4.141)$ & 0.002 & 0 & 0 & 1 \\
\hline Normal chest X-ray & $3(2.4)$ & $25(6.1)$ & $0.371(0.11-1.249)$ & 0.109 & 0 & 0 & 1 \\
\hline
\end{tabular}


Table 4 Univariate Analysis in the DC Using the MI Dataset (Continued)

\begin{tabular}{|c|c|c|c|c|c|c|c|}
\hline Pleural effusion & $25(19.7)$ & $37(9.1)$ & $2.458(1.414-4.271)$ & 0.001 & 0 & 0 & 1 \\
\hline Pneumonia & $21(16.5)$ & $27(6.6)$ & $2.796(1.52-5.143)$ & 0.001 & 0 & 0 & 1 \\
\hline Pulmonary congestion & $78(61.4)$ & $137(33.6)$ & $3.149(2.085-4.755)$ & $<0.001$ & 0 & 0 & 1 \\
\hline \multicolumn{8}{|l|}{$\mathrm{ECG}, n(\%)$} \\
\hline AF rhythm & $70(55.1)$ & $94(23)$ & 4.102 (2.699-6.236) & $<0.001$ & 0 & 0 & 1 \\
\hline HR (bpm), median (IQR) & $90(73-107)$ & $75(65.25-88)$ & $1.034(1.023-1.045)$ & $<0.001$ & 0 & 0 & 1 \\
\hline Normal ECG & $3(2.4)$ & $23(5.6)$ & $0.405(0.12-1.372)$ & 0.146 & 0 & 0 & 1 \\
\hline Other changes & $68(53.5)$ & $191(46.8)$ & $1.309(0.878-1.952)$ & 0.186 & 0 & 0 & 1 \\
\hline \multicolumn{8}{|l|}{ Blood tests, median (IQR) } \\
\hline Albumin $(\mathrm{g} / \mathrm{L}), n=122 / 391$ & $40.4(38.4-42.8)$ & $41.2(38.7-43.2)$ & $0.957(0.905-1.012)$ & 0.124 & 0.026 & 0.026 & 0.998 \\
\hline ALT (IU/L), $n=126 / 404$ & $19(15-29)$ & $20(14-27.5)$ & $1.001(0.992-1.01)$ & 0.849 & 0.001 & 0.001 & 1 \\
\hline APPT (s) & $31.7(28.1-35.1)$ & $32.2(29-35.4)$ & $0.993(0.97-1.015)$ & 0.52 & 0 & 0 & 1 \\
\hline AST (IU/L), $n=120 / 375$ & $27(20.4-32)$ & $23(18-30.3)$ & $1.001(0.995-1.008)$ & 0.697 & 0.031 & 0.032 & 0.998 \\
\hline Bilirubin, total $(\mu \mathrm{mol} / \mathrm{L}), n=117 / 380$ & $14.04(9.3-19.6)$ & $10.9(8.1-15.4)$ & $1.043(1.018-1.068)$ & 0.001 & 0.067 & 0.071 & 0.996 \\
\hline Creatinine ( $\mu \mathrm{mol} / \mathrm{L})$ & $89(77.7-104.9)$ & $91(79.9-106.7)$ & $0.998(0.991-1.006)$ & 0.638 & 0 & 0 & 1 \\
\hline Cholesterol, total $(\mathrm{mmol} / \mathrm{L}), n=113 / 354$ & $4.8(4-5.8)$ & $5.2(4.4-5.9)$ & $0.805(0.676-0.96)$ & 0.016 & 0.038 & 0.039 & 0.998 \\
\hline Fibrinogen $(\mathrm{g} / \mathrm{L}), n=121 / 381$ & $3.5(2.7-4.4)$ & $3.11(2.6-3.9)$ & $1.266(1.087-1.475)$ & 0.002 & 0.04 & 0.041 & 0.997 \\
\hline Glucose (mmol/L) & $7.5(6.4-9.7)$ & $6.6(5.8-7.9)$ & $1.061(1.009-1.117)$ & 0.021 & 0 & 0 & 1 \\
\hline Hematocrit, $n=126 / 407$ & $0.43(0.38-0.46)$ & $0.42(0.38-0.46)$ & $0.993(0.958-1.029)$ & 0.679 & 0 & 0 & 1 \\
\hline Hemoglobin (g/L) & $141(127-152)$ & $141(128.625-153)$ & $0.997(0.987-1.006)$ & 0.515 & 0 & 0 & 1 \\
\hline INR & $1.06(0.98-1.15)$ & $1.04(0.95-1.12)$ & $0.919(0.467-1.808)$ & 0.808 & 0 & 0 & 1 \\
\hline Platelet count $\left(\times 10^{9}\right.$ cells/L) & $236(186-286)$ & $248(206-309)$ & $0.998(0.995-1)$ & 0.048 & 0 & 0 & 1 \\
\hline Potassium (mmol/L), $n=126 / 404$ & $4(3.7-4.3)$ & $4(3.6-4.2)$ & $1.247(0.862-1.802)$ & 0.241 & 0.009 & 0.009 & 0.999 \\
\hline Protein, total $(\mathrm{g} / \mathrm{L}), n=126 / 397$ & $67.6(64-71.2)$ & $68(64.8-71.7)$ & $0.987(0.953-1.021)$ & 0.444 & 0.006 & 0.006 & 1 \\
\hline $\mathrm{PT}(\mathrm{s}), n=126 / 405$ & $12.2(11.3-13.8)$ & $11.8(10.8-16.1)$ & $0.976(0.932-1.022)$ & 0.305 & 0.002 & 0.002 & 1 \\
\hline $\mathrm{RBC}\left(\times 10^{12}\right.$ cells $\left./ \mathrm{L}\right)$ & $4.64(4.23-5.01)$ & $4.63(4.3-4.97)$ & $0.941(0.664-1.332)$ & 0.73 & 0 & 0 & 1 \\
\hline Sodium (mmol/L), $n=126 / 404$ & $139.3(138-141.9)$ & $139.5(138-141.3)$ & $1.015(0.957-1.077)$ & 0.624 & 0.011 & 0.011 & 0.999 \\
\hline Urea $(\mathrm{mmol} / \mathrm{L}), n=126 / 406$ & $6.36(5.2-8.5)$ & $5.81(4.5-7.3)$ & $1.089(1.02-1.161)$ & 0.01 & 0 & 0 & 1 \\
\hline WBC $\left(\times 10^{9}\right.$ cells/L) & $8.8(6.6-11.4)$ & $7.8(6.5-9.3)$ & $1.145(1.071-1.225)$ & $<0.001$ & 0 & 0 & 1 \\
\hline \multicolumn{8}{|l|}{ Antithrombotic medication, $n(\%)$} \\
\hline Anticoagulant & $5(4)$ & $23(5.6)$ & $0.693(0.258-1.863)$ & 0.468 & 0 & 0 & 1 \\
\hline Antiplatelet & $68(54)$ & $322(78.7)$ & $0.317(0.208-0.483)$ & $<0.001$ & 0 & 0 & 1 \\
\hline Anticoagulant + antiplatelet & $29(23)$ & $37(9.1)$ & $3.006(1.76-5.132)$ & $<0.001$ & 0 & 0 & 1 \\
\hline IV rtPA & $24(19)$ & $27(6.6)$ & $3.329(1.842-6.015)$ & $<0.001$ & 0 & 0 & 1 \\
\hline
\end{tabular}

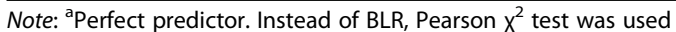

Table 5 Multivariate Analysis (DC, $n=535)$

\begin{tabular}{llllll}
\hline & Coefficient & Bias & Bootstrap SE & OR (95\% BCa Cl) & $p$-Value \\
\hline ASPECTS & -0.472 & -0.026 & 0.092 & $0.62(0.52-0.75)$ & $3.18(1.47-6.66)$ \\
AF on ECG & 1.157 & 0.029 & 0.405 & $2.41(1.12-5.15)$ & 0.002 \\
Male sex & 0.88 & 0.055 & 0.381 & $1.15(1.08-1.21)$ & 0.027 \\
NIHSS & 0.135 & 0.004 & 0.029 & $1.03(1.01-1.04)$ & $<0.001$ \\
HR on ECG (bpm) & 0.027 & 0.001 & 0.008 & $2.83(1.44-5.45)$ & 0.001 \\
HMCA sign & 1.041 & 0.001 & 0.346 & $0.04(0.01-0.22)$ & 0.002 \\
INR & -3.304 & -0.179 & 0.92 & $<0.001$ \\
\hline
\end{tabular}



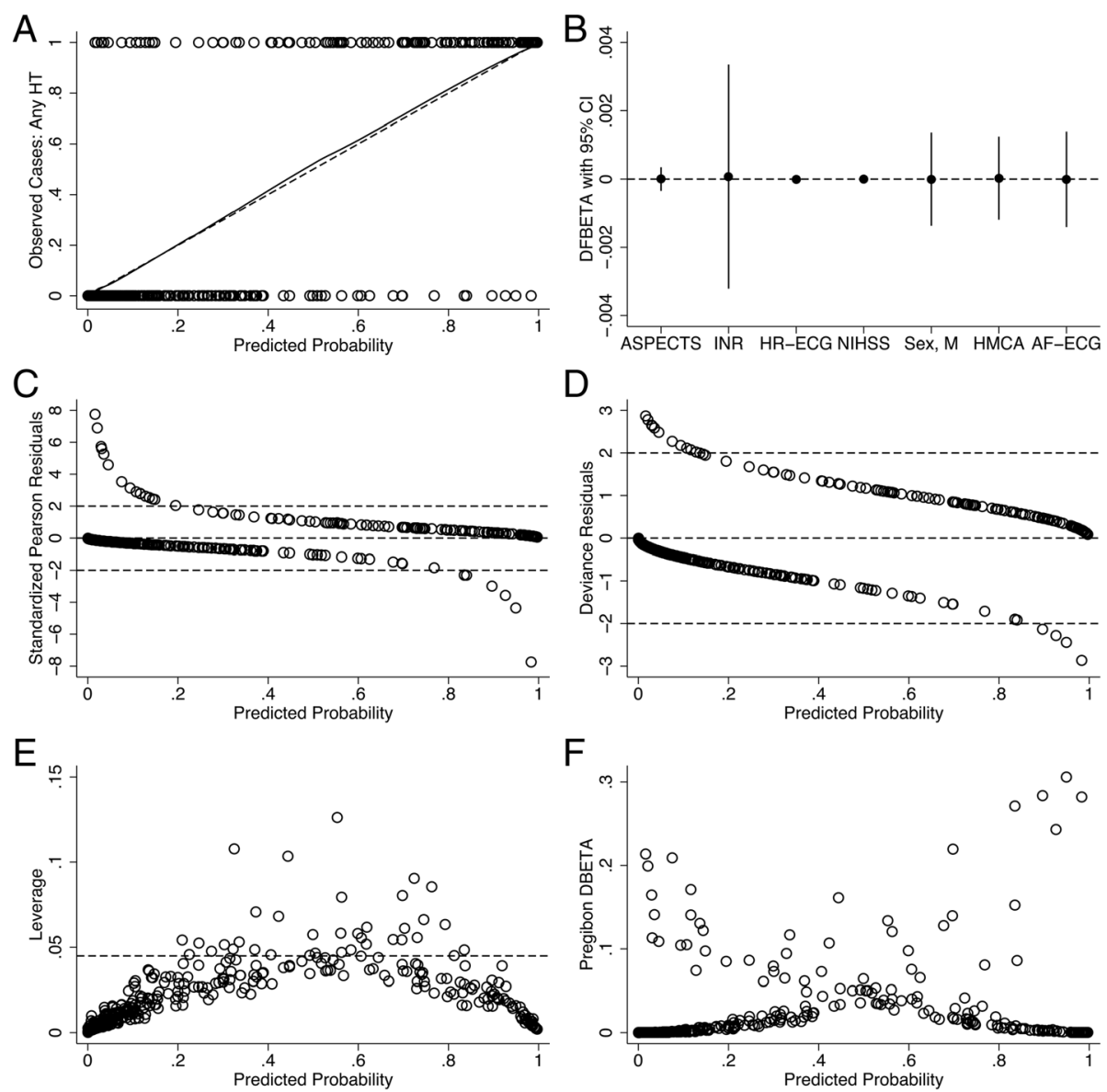

Fig. 1 Multivariate BLR Model Diagnostics. a LOWESS graph, bandwidth =0.8. Each hollow circle is an individual observation. $\mathbf{b}$ Influence of each individual observation on the coefficient estimate (dfbeta). c Standardized Pearson residuals. $\mathbf{d}$ Deviance residuals. e Leverage. The dashed line corresponds to the 3-fold leverage mean. f Pregibon's influential statistics (dbeta)

The eligible patients received diagnostic tests and treatment in accordance with current national stroke guidelines. The permissible hospital length of stay was at least 14 days, which was determined by the state mandatory medical insurance standard for AIS patients.

Clinical baseline variables, including age, sex, risk factors, pre-admission medication, stroke subtype according to the Trial of ORG 10172 in Acute Stroke Treatment classification, NIHSS score, vital signs, blood tests, electrocardiogram (ECG), echocardiogram, and chest X-ray findings at admission were extracted from the medical charts. The NIHSS score was routinely and systematically assessed by neurologists. The time of AIS onset was documented as described by the patient or witness; if unknown, it was considered to be the last time the patient was seen well. In-hospital antithrombotic medication was logged for 14 consecutive days; the log was withdrawn earlier if HT occurred.

\section{Imaging protocol}

Brain non-contrast computed tomography $(\mathrm{CT})$ was performed using a multidetector CT scanner (Aquilion 64;
Toshiba Medical Systems, Otawara, Japan). All CT scans were obtained with $0.5 \mathrm{~mm}$ slice thickness; the technical parameters were as follows: $120 \mathrm{kVp}, 300 \mathrm{~mA}$, rotation time $0.75 \mathrm{~s}$, matrix size $512 \times 512$, helical scan mode, total scan time $9.7 \mathrm{~s}$, reconstruction interval $5 \mathrm{~mm}$. Window levels and widths were optimized for gray/ white matter distinction. The Alberta Stroke Program Early CT score (ASPECTS), hyperdense MCA (HMCA) sign, and leukoaraiosis were routinely and systematically recorded at admission by radiologists. The HMCA sign was assessed by measurements of absolute attenuation of the affected and normal vessels. Absolute density of the affected MCA of $>43$ Hounsfield units and the MCA ratio of $>1.2$ on a non-contrast $\mathrm{CT}$ scan were regarded as the positive HMCA sign [11]. Diffuse hypodense areas involving the periventricular and/or centrum semiovale white matter were considered as leukoaraiosis. A followup CT scan was routinely done on hospitalization day 7 and 14 or at any time if required by a treating neurologist. All patients had at least one follow-up CT scan. 
Table 6 Derivation of the HTI Score

\begin{tabular}{|c|c|c|}
\hline & PP Range ${ }^{a}$ & Allocated Points \\
\hline \multicolumn{3}{|l|}{ ASPECTS } \\
\hline $10-7$ & $0.1-0.2$ & 0 \\
\hline $6-5$ & $0.2-0.3$ & 1 \\
\hline $4-3$ & $0.3-0.4$ & 2 \\
\hline $2-0$ & $>0.4$ & 3 \\
\hline \multicolumn{3}{|l|}{ NIHSS } \\
\hline $0-11$ & $0.1-0.2$ & 0 \\
\hline $12-17$ & $0.2-0.3$ & 1 \\
\hline $18-23$ & $0.3-0.4$ & 2 \\
\hline$>23$ & $>0.4$ & 3 \\
\hline \multicolumn{3}{|l|}{ INR } \\
\hline$>1.82$ & $<0.1$ & 0 \\
\hline $1.26-1.82$ & $0.1-0.2$ & 1 \\
\hline$\leq 1.25$ & $>0.2$ & 2 \\
\hline \multicolumn{3}{|c|}{ HR on ECG (bpm) } \\
\hline $40-68$ & $0.1-0.2$ & 0 \\
\hline 69-112 & $0.2-0.3$ & 1 \\
\hline $113-147$ & $0.3-0.4$ & 2 \\
\hline$>147$ & $>0.4$ & 3 \\
\hline AF on ECG & $0.2-0.3$ & 1 \\
\hline HMCA sign & $0.2-0.3$ & 1 \\
\hline Male sex & $0.2-0.3$ & 1 \\
\hline
\end{tabular}

Note: ${ }^{a}$ Holding all other variables constant at their observed values

\section{Outcome measures}

The outcome was retrospectively revised based on prospectively collected data. Any HT on a follow-up CT scan within 14 days after AIS onset was taken into account. A hemorrhage was considered symptomatic if it was not seen on a previous CT scan and there had subsequently been either a suspicion of hemorrhage or any decline in neurologic status [12]. According to the ECASS I trial [13], HT was further classified into hemorrhagic infarction type 1 (HI-1), or type 2 (HI-2), or parenchymal hematoma type 1 (PH-1), or type 2 (PH-2).

\section{Statistical analysis}

Multinomial logistic regression with relative risk ratio (RRR) estimation was used to highlight the AHT and SHT association with poor outcomes (death, malignant edema, and dependency defined as the modified Rankin scale of $>2$ at discharge); the baseline category was the HT-negative group.

The intraclass correlation coefficient (ICC) was computed to assess inter-rater agreement for the ASPECTS and NIHSS. In order to calculate the ICC for the NIHSS, the same set of video files with NIHSS examination from six patients with different stroke severity was demonstrated to seven neurologists who regularly admitted patients to our stroke unit. The ICC for the ASPECTS was obtained in the similar manner: the identical pool of brain non-contrast CT scans from 33 patients with different ischemic burden was presented to four radiologists, who regularly evaluated brain CT scans at admission. Each doctor was evaluated separately and independently; the NIHSS and ASPECTS reference manuals were available on request. He or she had a chance to make any corrections during the evaluation process, but was not allowed to do so after his or her assessment had been completed.

A preliminary data analysis showed that 14 variables in $39.21 \%$ of observations were missing (Table 1).

The data were not missing completely at random (Little's test: $\chi^{2}$ (1706), 2336.69; $\left.p<0.001\right)$. However, the omissions did occur accidentally because some tests were not available at the time of patient's admission or the results were lost. Moreover, the missing variables correlated with other collected data. Therefore, it was reasonable to assume that the data were missing at random and multiple imputation (MI) was an appropriate technique to manage the absent values (Table 2).

After obtaining the imputed data, the observations were divided into derivation (DC) and validation (VC) cohorts by generating Bernoulli variates with probability parameter 0.7 .

Descriptive statistics included median with interquartile range (IQR) and percentage for continuous (the distribution was not normal) and categorical data respectively. The NIHSS and ASPECTS were treated as continuous variables because of multiple categories. Lists of univariate and multivariate HT predictors were obtained by fitting a binary logistic regression (BLR) model. Variables with univariate $p$-value $\leq 0.25$ were further included in multivariate analysis, whereas only items with $p$-value $<0.05$ were kept in the multivariate BLR equation. Once the list of HT predictors was obtained by fitting a multivariate BLR model, we dropped the MI dataset because the included variables had no missing values in the source data.

In order to proceed with exploratory (EFA) and confirmatory (CFA) factor analysis, the Bartlett's test of sphericity, Kaiser-Meyer-Olkin measure, and DoornikHansen test were carried out to check for patterned relationships between the HTI items, data sufficiency, and multivariate normality respectively. EFA by means of principal factor (PF) and principal component factor (PCF) techniques was performed with varimax and promax rotations to assess dimensionality of the HTI items and to extract variables with shared variance; an eigenvalue cut-off was 1.0. CFA with maximum likelihood estimation was applied to select the final model; goodness of fit was assessed with the Satorra-Bentler scaled $X^{2}$ test to adjust for data non-normality. 

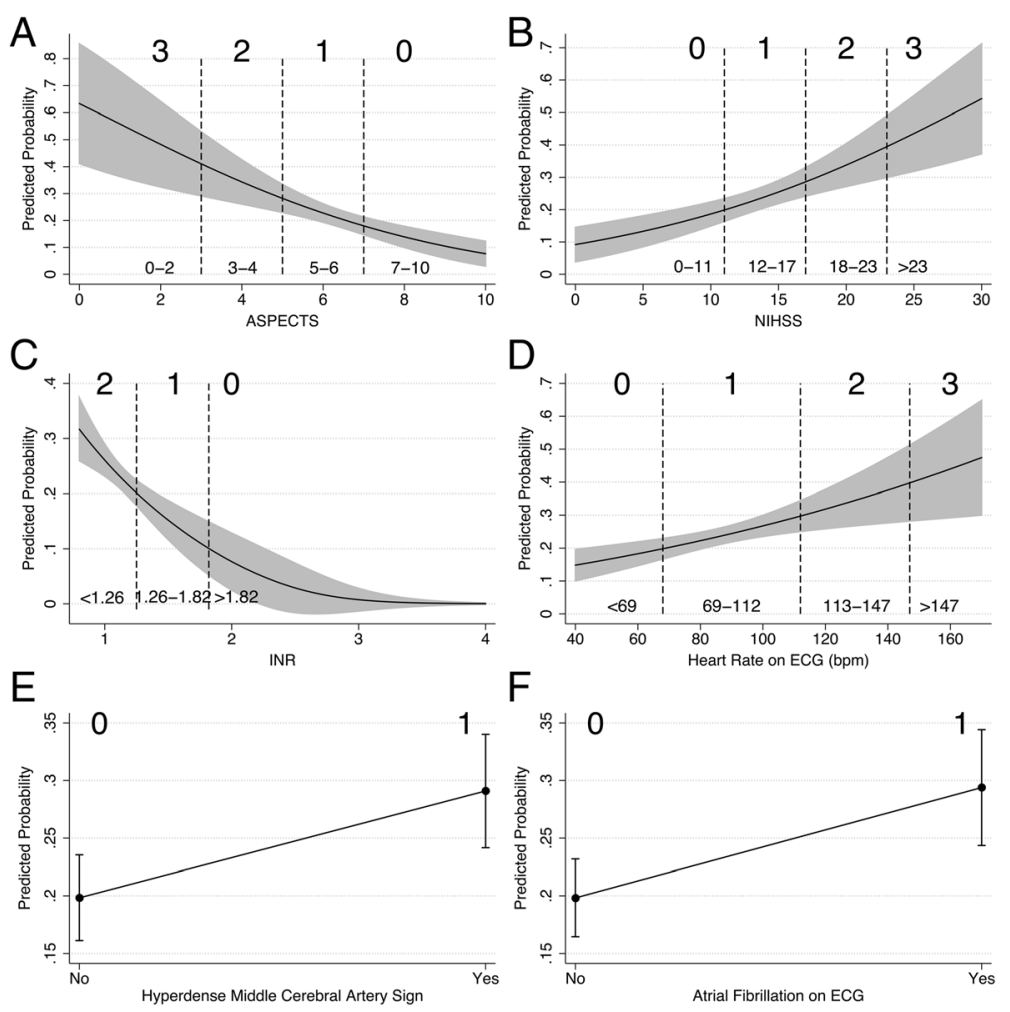

$\mathrm{F}$
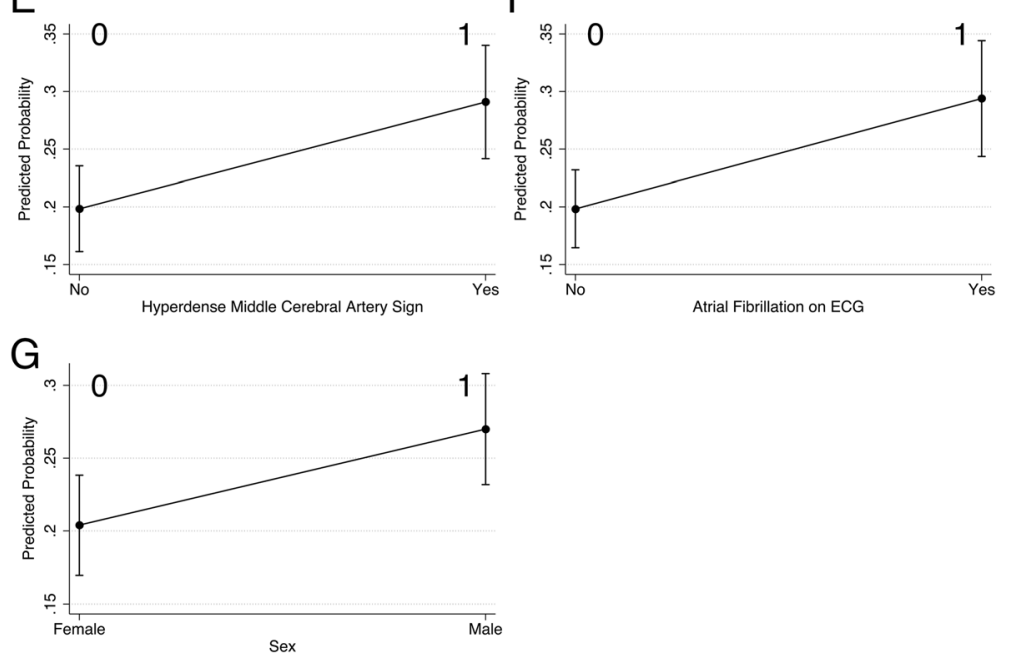

Fig. 2 Derivation of HTI Score. a ASPECTS. b NIHSS. c INR. d HR on ECG. e HMCA sign. $\mathbf{f}$ AF on ECG. $\mathbf{g}$ Sex. Grey areas and capped lines represent 95\% Cl. Numbers at the top indicate HTI scores; at the bottom, units of variables. The confounders are held constant at their observed values

HTI internal consistency reliability (ICR) was evaluated with the ordinal $\alpha$, Guttman $\lambda_{2}$ and $\lambda_{4}$ bounds, Raykov's $\rho$, McDonald's $\omega$, and greatest lower bound [14, 15]. The values $\geq 0.7$ were considered to be reliable. As the model included ordinal and dichotomous variables, a polychoric correlation matrix was used for EFA and ICR analysis except for McDonald's categorical $\omega$. The latter was computed by using the Green and Yang method [16].

The DC and VC were compared by using the MannWhitney $U$ and Pearson $X^{2}$ tests for continuous and categorical variables respectively. The equality of kernel density estimate (KDE) for predicted probability (PP) of any HT between the multivariate BLR model and HTI score as well as for HTI scores between the DC and VC was evaluated with the two-sample Kolmogorov-Smirnov test.

Receiver operating characteristic (ROC) analysis was conducted to assess prognostic performance. The optimal cutpoint score to distinguish between HT-positive and negative groups was defined with the Youden index. Based on the VC appraisal, the predictive ability of the HTI was compared with several alternative tools by testing the area under the ROC curve (AUC) of each score against the HTI one. For each comparison, the Šidák-adjusted $p$-value was reported. The AUC equality was evaluated by using the DeLong algorithm [17].

Whenever possible, bootstrapping was performed with 1000 samples and computing either adjusted for ties bias-corrected and accelerated (BCa) or normal-based (NB) confidence intervals (CI) to reduce sampling bias, overfitting, and prediction errors.

\section{Results}

Overall, HT occurred in 186 (23.8\%) out of 783 cases, whereas SHT was determined in 98 (12.5\%). HI-1 was established in 26 (3.3\%); HI-2, 120 (15.3\%); PH-1, 13 (1.7\%); and $\mathrm{PH}-2,27$ (3.4\%) observations. Patients with 

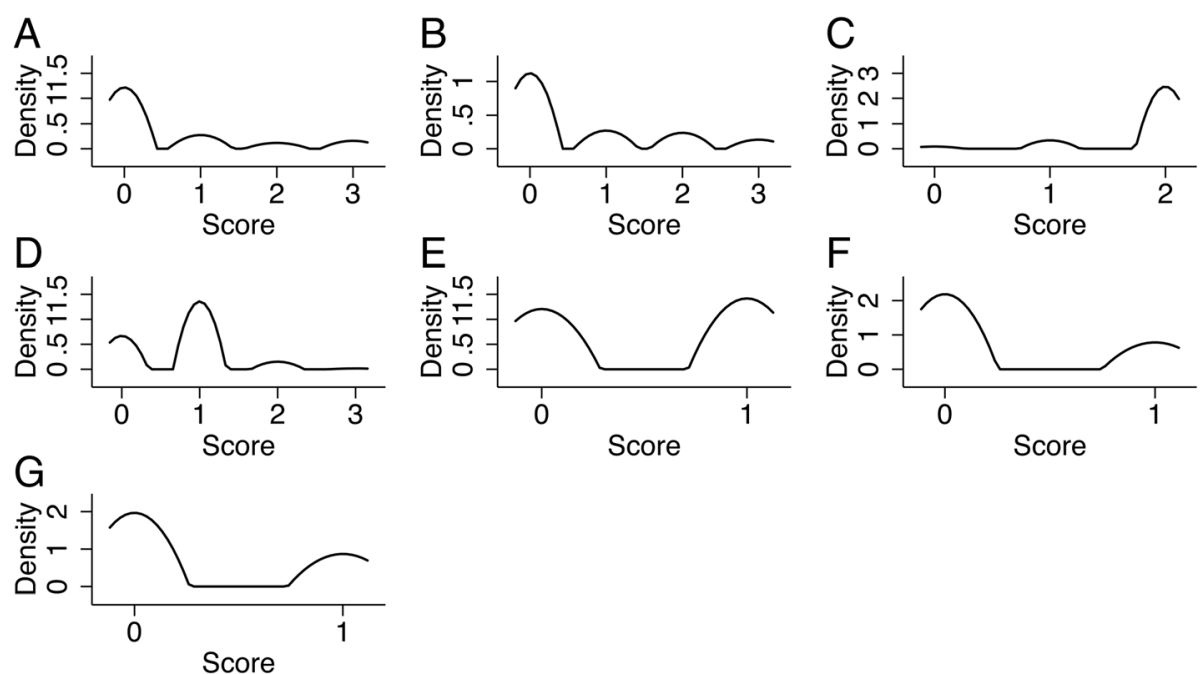

Fig. $3 \mathrm{KDE}$ for HTI Items. Kernel = Epanechnikov for all items. a ASPECTS; bandwidth = 0.1899. b NIHSS; bandwidth = 0.1899. $\mathbf{c}$ INR; bandwidth $=0.116$. $\mathbf{d}$ HR on ECG; bandwidth $=0.1528$. e Sex; bandwidth $=0.1278$. $\mathbf{f} \mathrm{HMCA}$ sign; bandwidth $=0.113$. $\mathbf{g}$ AF on ECG; bandwidth $=0.1182$

any HT were more likely to have a poor outcome: death (AHT: RRR, 4.8; 95\% CI, 2.2-10.6; $p<0.001$; SHT: RRR, 11.7; 95\% CI, 6-22.6; $p<0.001$ ), malignant edema (AHT: RRR, 16.7; 95\% CI, 5.6-49.2; $p<0.001 ;$ SHT: RRR, 52.1; 95\% CI, 19.6-138.9; $p<0.001)$, and dependency (AHT: RRR, 4.4; 95\% CI, 2.5-7.7; $p<0.001$; SHT: RRR, 30.4; 95\% CI, 9.5-97.1; $p<0.001)$.

There was no difference between AHT and SHT groups with regard to timing $(p=0.08)$ : the former, median day 2 (IQR, 1-4); the latter, median day 2 (IQR, 1$3)$. The median AIS onset time was $6 \mathrm{~h}$ (IQR, 2-11). Just under half of all cases $(346 ; 44.2 \%)$ were admitted within the 4.5-h therapeutic window; in total, 67 (8.6\%) patients were treated with IV rtPA.

The ICC was 0.95 (95\% CI, 0.85-0.99; $p<0.001)$ and 0.78 (95\% CI, 0.59-0.88; $p<0.001$ ) for the NIHSS and ASPECTS respectively, which indicated excellent inter- rater agreement. There was no difference between the DC and VC (Table 3).

Univariate analysis was summarized in Table 4.

\section{Multivariate analysis}

Although univariate $p$-values for leukoaraiosis and international normalized ratio (INR) were above our acceptable threshold, we included them in the multivariate analysis because some authors had proposed them as risk factors $[18,19]$. As a result of fitting a multivariate BLR model, seven variables were kept in the final equation (Table 5).

Swapping AF on ECG for the AF history variable increased the Bayesian and Akaike information criteria by 1.18, which slightly favored the initial model. Overall, the multivariate BLR model was statistically significant (Wald test: $\chi^{2}(7), 87.76 ; p<0.001 ;-2 \log$-likelihood,

Table 7 Factor/Component Loadings and Uniqueness in EFA of the HTI Items

\begin{tabular}{|c|c|c|c|c|c|c|c|c|c|}
\hline & \multicolumn{3}{|c|}{ No Rotation } & \multicolumn{2}{|c|}{ Varimax Rotation } & \multicolumn{2}{|c|}{ Promax Rotation } & \multicolumn{2}{|c|}{ Uniqueness } \\
\hline & F1 & $\mathrm{C} 1$ & $\mathrm{C} 2$ & $\mathrm{C} 1$ & $\mathrm{C} 2$ & C1 & $\mathrm{C} 2$ & PF & PCF \\
\hline ASPECTS & 0.84 & 0.86 & & 0.9 & & 0.9 & & 0.29 & 0.17 \\
\hline HR on ECG & 0.34 & 0.43 & -0.6 & & 0.73 & & 0.75 & 0.89 & 0.45 \\
\hline INR & & & 0.56 & & -0.54 & & -0.58 & 0.99 & 0.68 \\
\hline $\mathrm{NIHSS}$ & 0.83 & 0.86 & & 0.89 & & 0.89 & & 0.32 & 0.18 \\
\hline Male sex & -0.33 & -0.43 & & & -0.4 & & -0.39 & 0.89 & 0.76 \\
\hline HMCA sign & 0.81 & 0.84 & 0.36 & 0.91 & & 0.91 & & 0.35 & 0.18 \\
\hline AF on ECG & 0.56 & 0.65 & -0.59 & & 0.83 & & 0.82 & 0.69 & 0.23 \\
\hline Eigenvalue & 2.58 & 2.98 & 1.38 & NA & NA & NA & NA & NA & NA \\
\hline Variance, $\%$ & 82.8 & 42.5 & 19.76 & 37.56 & 24.7 & 39.33 & 28.1 & NA & NA \\
\hline
\end{tabular}

Note: Empty cells indicate that absolute factor or component loading value is <0.3. C1 stands for Component 1, C2 Component 2, F1 Factor 1, and NA Not applicable 
Table 8 CFA. Goodness of Fit Statistics

\begin{tabular}{|c|c|c|c|c|c|c|}
\hline & F1-V4 & F1-V5 & F1-V6 & F1-V7 & $\mathrm{F} 2$ & Description \\
\hline \multicolumn{7}{|l|}{ Likelihood ratio } \\
\hline$x^{2}(2 / 5 / 9 / 14 / 13)$ & 0.5 & 56.17 & 87.26 & 103.66 & 18.19 & \multirow[t]{2}{*}{ Model vs. saturated } \\
\hline$p$-value & 0.78 & $<0.001$ & $<0.001$ & $<0.001$ & 0.15 & \\
\hline$x^{2}(6 / 10 / 15 / 21 / 21)$ & 594.14 & 664.18 & 711.01 & 727.4 & 727.4 & \multirow[t]{2}{*}{ Baseline vs. saturated } \\
\hline$p$-value & $<0.001$ & $<0.001$ & $<0.001$ & $<0.001$ & $<0.001$ & \\
\hline \multicolumn{7}{|l|}{ Satorra-Bentler test } \\
\hline$x^{2}(2 / 5 / 9 / 14 / 13)$ & 0.4 & 50.96 & 82.63 & 100.31 & 18.08 & \multirow[t]{2}{*}{ Model vs. saturated } \\
\hline$p$-value & 0.82 & $<0.001$ & $<0.001$ & $<0.001$ & 0.16 & \\
\hline$x^{2}(6 / 10 / 15 / 21 / 21)$ & 475.75 & 574.14 & 649.06 & 684.79 & 684.79 & \multirow[t]{2}{*}{ Baseline vs. saturated } \\
\hline$p$-value & $<0.001$ & $<0.001$ & $<0.001$ & $<0.001$ & $<0.001$ & \\
\hline \multicolumn{7}{|l|}{ Population error } \\
\hline RMSEA & $<0.001$ & 0.138 & 0.127 & 0.109 & 0.027 & \multirow[t]{2}{*}{$\begin{array}{l}\text { Root mean squared error of } \\
\text { approximation }\end{array}$} \\
\hline $90 \% \mathrm{Cl}$ & $0-0.056$ & $0.107-0.172$ & $0.104-0.153$ & $0.09-0.13$ & $0-0.054$ & \\
\hline$p$-close & 0.932 & $<0.001$ & $<0.001$ & $<0.001$ & 0.909 & Probability RMSEA $\leq 0.05$ \\
\hline RMSEA-SB & $<0.001$ & 0.131 & 0.124 & 0.107 & 0.027 & Satorra-Bentler RMSEA \\
\hline \multicolumn{7}{|l|}{ Information criteria } \\
\hline AIC & 3726.82 & 4682.79 & 5446.18 & 6121.68 & 6038.21 & Akaike information criterion \\
\hline $\mathrm{BIC}$ & 3778.21 & 4747.02 & 5523.26 & 6211.6 & 6132.42 & Bayesian information criterion \\
\hline \multicolumn{7}{|l|}{ Baseline comparison } \\
\hline $\mathrm{CFI}$ & 1 & 0.92 & 0.89 & 0.87 & 0.99 & Comparative fit index \\
\hline TLI & 1 & 0.84 & 0.81 & 0.81 & 0.99 & Tucker-Lewis index \\
\hline CFI-SB & 1 & 0.92 & 0.88 & 0.87 & 0.99 & Satorra-Bentler CFI \\
\hline TLI-SB & 1 & 0.84 & 0.81 & 0.81 & 0.99 & Satorra-Bentler TLI \\
\hline \multicolumn{7}{|l|}{ Size of residuals } \\
\hline SRMR & 0.01 & 0.08 & 0.08 & 0.08 & 0.03 & $\begin{array}{l}\text { Standardized root mean } \\
\text { squared residual }\end{array}$ \\
\hline$C D$ & 0.83 & 0.83 & 0.83 & 0.83 & 0.96 & Coefficient of determination \\
\hline
\end{tabular}

Note: F1-V4 indicates one-factor model with 4 variables (ASPECTS, NIHSS, HMCA sign, and AF on ECG), F1-V5 one-factor model with 5 variables (4 previous variables $+\mathrm{HR}$ on ECG), F1-V6 one-factor model with 6 variables (5 previous variables + sex), F1-V7 one-factor model with 7 variables (6 previous variables + INR), and F2 two-factor model with factor 1 (ASPECTS, NIHSS, and HMCA sign) and factor 2 (AF on ECG, INR, sex, and HR on ECG)
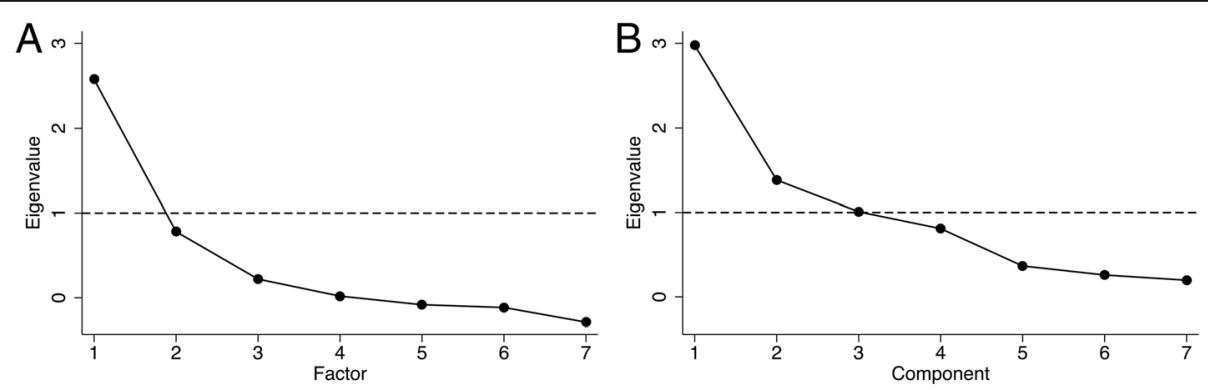

Fig. 4 Scree Plot. EFA by using (a) PF and (b) PCF methods 
Table 9 BLR Coefficients, Bias, and Bootstrap SE for the HTI (DC, $n=535)$

\begin{tabular}{|c|c|c|c|c|c|c|}
\hline & \multicolumn{3}{|l|}{ Crude } & \multicolumn{3}{|l|}{ Adjusted $^{a}$} \\
\hline & Coefficient & Bias & $\begin{array}{l}\text { Bootstrap } \\
\text { SE }\end{array}$ & Coefficient & Bias & $\begin{array}{l}\text { Bootstrap } \\
\text { SE }\end{array}$ \\
\hline $\begin{array}{l}\mathrm{HTI}, \\
\text { overall }\end{array}$ & 0.941 & 0.012 & 0.085 & 1.03 & 0.027 & 0.109 \\
\hline \multicolumn{7}{|l|}{ HTI items } \\
\hline ASPECTS & 0.815 & 0.031 & 0.165 & 0.914 & 0.047 & 0.188 \\
\hline NIHSS & 0.958 & 0.02 & 0.175 & 1.053 & 0.038 & 0.201 \\
\hline $\begin{array}{l}\text { HMCA } \\
\text { sign }\end{array}$ & 1.157 & -0.005 & 0.336 & 1.214 & 0.008 & 0.347 \\
\hline $\begin{array}{l}\text { AF on } \\
\text { ECG }\end{array}$ & 1.115 & 0.002 & 0.317 & 1.214 & 0.031 & 0.403 \\
\hline
\end{tabular}

Note: ${ }^{\mathrm{a} C o n f o u n d e r s ~(s e x, ~ I N R, ~ a n d ~ H R ~ o n ~ E C G) ~ w e r e ~ m e a s u r e d ~ i n ~ a l l o c a t e d ~}$ points (Table 6)

271.93; Cox-Snell pseudo- $R^{2}, 0.44$; Nagelkerke pseudo$R^{2}, 0.67$ ). It explained variance of $78.4 \%$ (variance of latent variable, $y^{*}=11.13$; error, $\varepsilon=3.29$ ) and fitted the data well (Hosmer-Lemeshow goodness of fit test for 10 groups: $\left.\chi^{2}(8), 6.87 ; p=0.551\right)$. Neither significant interactions nor polynomial terms were found.

There was no specification error (Pregibon's link test: linear predicted value, $p<0.001$; linear predicted value squared, $p=0.54$ ). Assumption of linearity between independent variables and log odds was confirmed by the LOWESS graph. Multicollinearity was not an issue: the extrema of the variance inflation factor were 1.01 and 2.29 .

Although standardized Pearson and deviance residuals exceeded 2 in a few observations, their leverage and Pregibon's influential statistics (dbeta) turned out to be very small. Moreover, removing those observations did not significantly change the equation coefficients. Influence of each individual observation on the coefficient estimate (not adjusted for the covariate pattern), dfbeta, was not strong. However, the most sensitive was the INR variable (Fig. 1).
Model sensitivity, specificity, positive and negative predictive values were $76.2 \%, 95.6 \%, 84.2 \%$, and $92.9 \%$ respectively. The model accurately classified $91 \%$ of the observations, whereas the equation without any independent variables classified correctly only $76.5 \%$ of the cases.

Based on PP tables and plots, we divided each predictor into categories and allocated them points according to the PP range in order to draw the HTI score. Given the Doornik-Hansen test $\left(\chi^{2}(14), 3665.64 ; p<0.001\right)$, the distribution of the newly derived HTI items was not multivariate normal (Table 6; Figs. 2 and 3).

\section{Factor analysis}

The Bartlett's test of sphericity $\left(\chi^{2}(21), \quad 721.74\right.$; $p<0.001)$ and the Kaiser-Meyer-Olkin measure of 0.71 demonstrated that the HTI items did have patterned relationships and were sufficient for EFA. PF EFA established a unidimensional scale, i.e. there was only one factor that explained a cumulative variance of $82.8 \%$. By means of PCF EFA, the factor was discovered to consist of cerebral (ASPECTS, NIHSS, and HMCA sign) and extracerebral (resting heart rate (HR) on ECG, AF on ECG, sex, and INR) components as we called them. However, the resting HR on ECG, INR, and sex variables showed high uniqueness values and low factor loadings; therefore, we had to drop them. The final 4-item HTI was strongly supported by subsequent CFA (Tables 7 and 8; Fig. 4).

Once the HTI was definitively established, crude PP of any HT was computed for each score by using BLR. Although the dropped items were no longer a part of the HTI, we put them into the BLR equation for confounding adjustment. Unsurprisingly, the confounders exerted only a minor influence on the overall HTI OR by increasing it up to $12 \%$ and had no significant effect on the OR of the separate HTI items (Tables 9, 10 and 11; Fig. 5).

KDE for PP of any HT was equal between the multivariate BLR model and HTI score $(D=0.184$; $p=0.371)$. Thus, the HTI score was considered as a surrogate for the multivariate BLR model (Fig. 6).

Table 10 OR for the HTI (DC, $n=535)$

\begin{tabular}{|c|c|c|c|c|c|c|}
\hline & \multicolumn{2}{|l|}{ Crude } & \multicolumn{2}{|l|}{ Adjusted $^{a}$} & \multicolumn{2}{|c|}{ Crude vs. Adjusted $^{b}$} \\
\hline & OR (95\% BCa Cl) & $p$-Value & $\overline{\mathrm{OR}}(95 \% \mathrm{BCa} \mathrm{Cl})$ & $\overline{p \text {-Value }}$ & $x^{2}(1)$ & $p$-Value \\
\hline $\mathrm{HTI}$, overall & $2.56(2.19-3.02)$ & $<0.001$ & $2.80(2.32-3.39)$ & $<0.001$ & 4.03 & 0.045 \\
\hline \multicolumn{7}{|l|}{ HTI items } \\
\hline ASPECTS & $2.26(1.64-3.07)$ & $<0.001$ & $2.49(1.75-3.54)$ & $<0.001$ & 2.4 & 0.121 \\
\hline NIHSS & $2.61(1.88-3.7)$ & $<0.001$ & $2.87(1.91-4.15)$ & $<0.001$ & 1.91 & 0.167 \\
\hline HMCA sign & $3.18(1.71-6.24)$ & 0.001 & $3.37(1.73-6.89)$ & $<0.001$ & 0.33 & 0.565 \\
\hline AF on ECG & $3.05(1.71-5.88)$ & $<0.001$ & $3.37(1.55-7.4)$ & 0.003 & 0.27 & 0.605 \\
\hline
\end{tabular}

Note: ${ }^{a}$ Confounders (sex, INR, and HR on ECG) were measured in allocated points (Table 6). ${ }^{b}$ Wald test was performed 
Table 11 PP of Any HT for Each HTI Score

\begin{tabular}{llllll}
\hline HTI Score & Crude & & & Adjusted $^{\mathrm{a}}$ & \\
\cline { 2 - 3 } \cline { 5 - 6 } & PP $(95 \% \mathrm{Cl})$ & $p$-Value & & PP $(95 \% \mathrm{Cl})$ & $p$-Value \\
\hline 0 & $0.03(0.015-0.044)$ & $<0.001$ & & $0.027(0.011-0.042)$ & 0.001 \\
1 & $0.073(0.047-0.099)$ & $<0.001$ & & $0.07(0.043-0.098)$ & $<0.001$ \\
2 & $0.168(0.126-0.21)$ & $<0.001$ & & $0.169(0.125-0.213)$ & $<0.001$ \\
3 & $0.34(0.274-0.407)$ & $<0.001$ & & $0.346(0.275-0.417)$ & $<0.001$ \\
4 & $0.569(0.479-0.66)$ & $<0.001$ & & $0.571(0.474-0.668)$ & $<0.001$ \\
5 & $0.772(0.686-0.858)$ & $<0.001$ & & $0.768(0.676-0.861)$ & $<0.001$ \\
6 & $0.897(0.838-0.955)$ & $<0.001$ & & $0.893(0.829-0.957)$ & $<0.001$ \\
7 & $0.957(0.925-0.989)$ & $<0.001$ & & $0.956(0.92-0.992)$ & $<0.001$ \\
8 & $0.983(0.967-0.998)$ & $<0.001$ & & $0.983(0.965-1.0)$ & $<0.001$ \\
\hline
\end{tabular}

Note: ${ }^{\mathrm{a}}$ Confounders (sex, INR, and HR on ECG) were held constant at their observed values

\section{ICR and ROC analysis}

Given multiple reliability tests, HTI ICR was considered to be fair enough for the DC and VC alike. There was also no difference in the AUC $\left(\chi^{2}(1), 0.01 ; p=0.93\right)$ and KDE for the HTI scores ( $\mathrm{D}=0.02 ; p=1.0$ ) between both cohorts (Table 12; Fig. 7).

Taking into account that alternative scores had been developed in AIS patients with slightly different clinical settings, the HTI prognostic performance was considered to be at least non-inferior to the competitors (Tables 13 and 14).

\section{Discussion}

The incidence of HT showed in our study echoes the rate reported in literature. We have also reaffirmed the concept that AHT is not clinically innocuous. The study unequivocally reiterates infarct size, stroke severity, large-artery occlusion, and cardioembolism defined by ASPECTS, NIHSS, HMCA sign, and AF respectively are well-established independent HT predictors [20, 21]. In our HTI score, we use the presence of AF on ECG at admission rather than AF history for the reason discussed in the Results. However, other known predictors - platelet count, cholesterol level, age, hypertension, renal failure, hyperglycemia, and leukoaraiosis - have shown no independent association with any HT in our cohort; similar results were obtained by other authors [22-26]. The mechanism of this association needs to be explored.

Although women tend to be more likely HT-positive in our univariate BLR model, multivariate analysis reveals the opposite. It seems there is still controversy about the sex propensity for developing HT [27].

Accelerated HR at rest is known to be associated with an increased risk of stroke especially recurrent [28]. Since AIS commonly induces change in cardiovascular responses, post-stroke HR at admission could be a potential marker to identify patients at risk for short-term deterioration and long-term poor outcomes [29]. To the best of our knowledge, we have not found any literature, concerning HR correlations with HT. Here, we report that the more the HR is accelerated on ECG (but not the pulse rate), the more likely HT can occur.

Hypercoagulability at AIS onset measured by INR and other tests is known to be associated with an increased thrombotic tendency. As long as the hypercoagulable state persists, both arterial and venous thromboembolic recurrences can be expected. The association of these coagulation abnormalities with HT is not always clear [30]. As we have shown here, the less the INR, the higher the risk of HT.

Having identified seven independent variables in our multivariate analysis, we applied the PP range followed by factor analysis to assigned HTI scores and to regroup HTI variables into a limited set of clusters based on shared variance. We assume probability is more intuitive for interpreting than OR. In contrast, authors of other predictive tools allocated scores based on OR changes only [5-9, 31-33]. While BLR analyzes effects of each individual predictor on the dependent variable, factor analysis isolating constructs and concepts treats the model as a whole [34]. Thus, it helped us to avoid overfitting.

Among the compared predictive tools, the SPAN-100 and HeRS were derived from the cohorts, which were
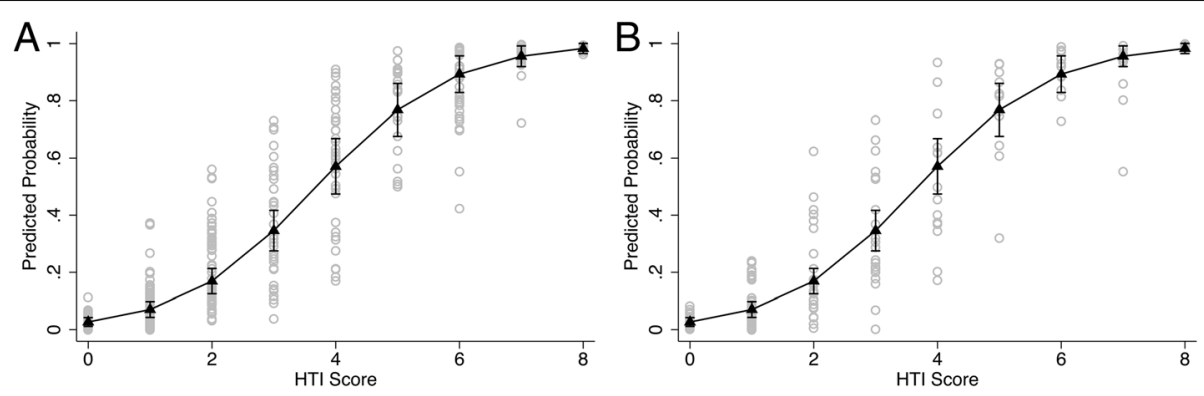

Fig. 5 Calibration Plot. The scatterplots display PP of any HT for individual observations obtained from multivariate analysis (Table 5) and arranged by the HTI score: (a) The DC, (b) The VC. The superimposed connected line graph drawn from the DC demonstrates PP of any HT for each HTI score with 95\% Cl adjusted for sex, INR, and HR on ECG (Table 11). The confounders are held constant at their observed values 


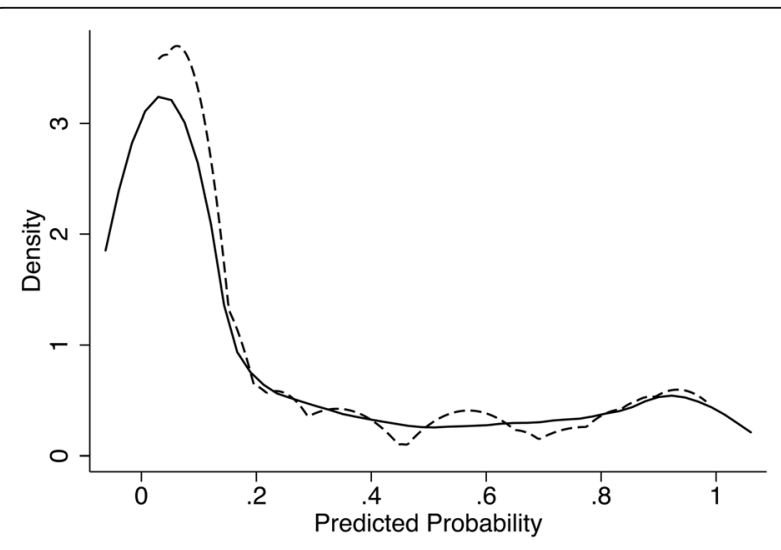

Fig. 6 KDE for PP of Any HT. Kernel = Epanechnikov, bandwidth $=0.0623$. The solid line represents the multivariate BLR model (Table 5); the dashed line, the HTI score (Table 11)

very similar in clinical settings to ours (Table 13). As to the former, we have reaffirmed that it is far inferior in prognostic performance to other scores $[35,36]$. Regarding the latter, the infarct size was measured in different ways: we chose the ASPECTS estimation on noncontrast CT, whereas the HeRS scored it in milliliters on magnetic resonance diffusion-weighted imaging (DWI MRI). Although both approaches are widely acceptable in hyperacute stroke settings, the ASPECTS is more suitable for non-contrast CT assessment, while the lesion volume can easily be quantified on DWI [37-39]. Furthermore, the ASPECTS, as well as the NIHSS, correlates strongly with the infarct volume (ASPECTS: Spearman $\rho,-0.88 ; p<0.001$; NIHSS: Spearman $\rho, 0.71$; $p<0.001$; VC, $n=248$ ), but moderately with each other

Table $12 \mathrm{HTI}$ ICR and ROC Analysis

\begin{tabular}{lll}
\hline & $\mathrm{DC}, n=535$ & $\mathrm{VC}, n=248$ \\
\hline Ordinal a & 0.82 & 0.83 \\
Guttman bounds & & \\
$\lambda_{2}$ & 0.83 & 0.85 \\
$\lambda_{4}$ & 0.84 & 0.88 \\
Raykov's $\rho$ & 0.81 & 0.81 \\
McDonald's $\omega$ & & \\
Categorical (95\% BCa Cl) & $0.81(0.77-0.84)$ & $0.82(0.76-0.86)$ \\
Hierarchical & 0.83 & 0.87 \\
Total & 0.89 & 0.91 \\
Greatest lower bound & 0.84 & 0.89 \\
ROC analysis (95\% NB Cl) & & \\
AUC & $0.85(0.82-0.89)$ & $0.83(0.78-0.88)$ \\
Youden index & $0.7(0.63-0.78)$ & $0.67(0.57-0.77)$ \\
Cutpoint & $2(1-3)$ & $2(1-3)$ \\
Sensitivity & $0.82(0.73-0.9)$ & $0.8(0.66-0.94)$ \\
Specificity & $0.89(0.8-0.97)$ & $0.87(0.73-1.0)$ \\
\hline
\end{tabular}

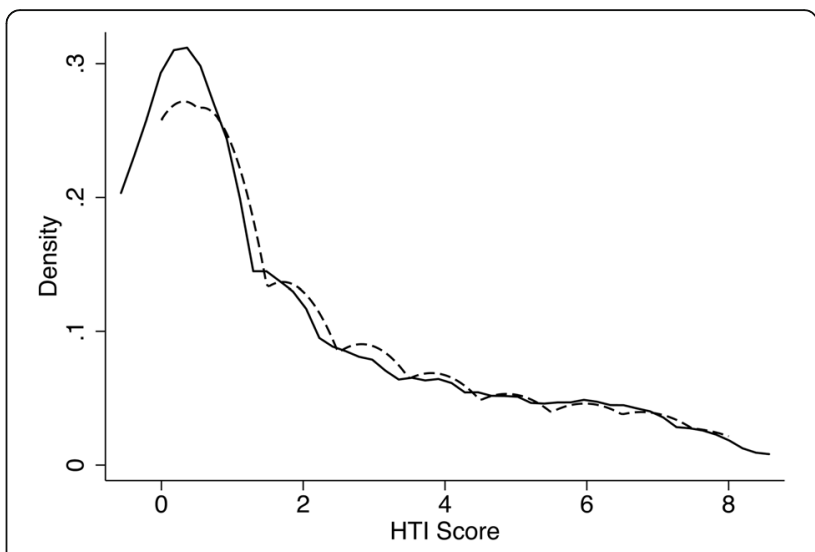

Fig. 7 KDE for HTI Scores. Kernel = Epanechnikov, bandwidth $=0.5697$. The solid line represents the DC; the dashed line, the VC

(Spearman $\rho,-0.66 ; p<0.001 ; \mathrm{VC}, n=248)$. If the stroke volume variable had been added to our multivariate BLR equation, a multicollinearity issue would have occurred. We also suppose that a combination of clinical and imaging features is more reliable than the imaging data alone. To make our HTI score as much easy-to-use as possible, we have purposely refrained from MRI since $\mathrm{CT}$ is readily available in the most hospitals. Moreover, the HeRS score is computationally complicated; therefore, it seems less attractive from the practical point of view.

There are some important peculiarities between posterior and anterior circulation stroke. The differences include the value of screening instruments, optimum diagnostic modalities, clinical features, and outcomes $[40,41]$. For instance, patients with vertebrobasilar infarction have lower NIHSS score and HT rates, less often AF, higher blood glucose level and rates of falsenegative DWI findings, more WBC counts, and a better long-term outcome than those with carotid stroke [42-44]. However, all aforementioned tools predict HT regardless of the vascular basin (Table 13). Moreover, scores with imaging modalities, like the HAT and SEDAN, include CT signs of MCA stroke only. Meanwhile, a scoring system, the pc-ASPECTS, has been developed and validated for posterior circulation stroke [45]. Thus, the accuracy of predictive tools could be further improved by distinguishing the infarcted vascular basins; therefore, we have decided to restrict our study to the MCA territory.

There are a few limitations in our study. A relatively small, but sufficient for statistical inferences, sample size and lack of ethnic and racial diversity could be a source of potential bias. Almost all patients came from our local community, which was populated with Russian, Tatar, and Jewish ethnic groups; there were no patients of African, Asian or Hispanic origin. Furthermore, AIS patients following endovascular interventions were excluded 
Table 13 Comparison of Different Composite Scores for Predicting HT in AIS Patients

\begin{tabular}{|c|c|c|c|c|c|c|}
\hline Score & Predictors & & $\begin{array}{l}\text { Sample } \\
\text { Size }\end{array}$ & $\begin{array}{l}\text { Cerebral Vascular } \\
\text { Territory }\end{array}$ & $\begin{array}{l}\text { Predicted } \\
\text { Outcome }\end{array}$ & $\begin{array}{l}\text { IV rtPA } \\
\text { Settings }\end{array}$ \\
\hline \multirow{2}{*}{$\begin{array}{l}\text { Cucchiara } \\
{[6]}\end{array}$} & Clinical & Age, NIHSS & \multirow[t]{2}{*}{1205} & \multirow[t]{2}{*}{ Any } & \multirow[t]{2}{*}{ Any HT } & \multirow[t]{2}{*}{ Yes } \\
\hline & Laboratory & Glucose, platelet count & & & & \\
\hline \multirow{2}{*}{$\begin{array}{l}\text { GRASPS } \\
{[9]}\end{array}$} & Clinical & Age, ethnicity, NIHSS, sex, SBP & \multirow[t]{2}{*}{10,242} & \multirow[t]{2}{*}{ Any } & \multirow[t]{2}{*}{$\mathrm{SHT}$} & \multirow[t]{2}{*}{ Yes } \\
\hline & Laboratory & Glucose & & & & \\
\hline \multirow{2}{*}{$\begin{array}{l}\text { HAS-BLED } \\
{[46]}\end{array}$} & Clinical & Age, alcohol abuse, bleeding history, drugs, SBP, stroke/TIA & \multirow[t]{2}{*}{3978} & \multirow[t]{2}{*}{ Any } & \multirow{2}{*}{$\begin{array}{l}\text { Major } \\
\text { Bleeding }^{\mathrm{a}}\end{array}$} & \multirow[t]{2}{*}{ No } \\
\hline & Laboratory & Liver and renal function tests, INR & & & & \\
\hline \multirow[t]{3}{*}{ HAT [5] } & Clinical & Diabetes mellitus, NIHSS & \multirow[t]{3}{*}{400} & \multirow[t]{3}{*}{ Any } & \multirow[t]{3}{*}{ SHT } & \multirow[t]{3}{*}{ Yes } \\
\hline & Imaging & ASPECTS & & & & \\
\hline & Laboratory & Glucose & & & & \\
\hline \multirow[t]{3}{*}{ HeRS [31] } & Clinical & Age & \multirow[t]{3}{*}{345} & \multirow[t]{3}{*}{ Any } & \multirow[t]{3}{*}{ Any HT } & \multirow[t]{3}{*}{ Regardless } \\
\hline & Imaging & Infarct volume & & & & \\
\hline & Laboratory & Estimated glomerular filtration rate & & & & \\
\hline \multirow[t]{3}{*}{ HTI } & Clinical & NIHSS & \multirow[t]{3}{*}{783} & \multirow[t]{3}{*}{ MCA } & \multirow[t]{3}{*}{ Any HT } & \multirow[t]{3}{*}{ Regardless } \\
\hline & Imaging & ASPECTS, HMCA sign & & & & \\
\hline & Laboratory & AF on ECG & & & & \\
\hline \multirow[t]{2}{*}{ iScore [32] } & Clinical & $\begin{array}{l}\text { AF, age, cancer, chronic heart failure, NIHSS, preadmission disability, } \\
\text { renal dialysis, sex, stroke subtype }\end{array}$ & \multirow[t]{2}{*}{1696} & \multirow[t]{2}{*}{ Any } & \multirow[t]{2}{*}{ Any HT } & Yes \\
\hline & Laboratory & Glucose & & & & \\
\hline SEDAN [8] & Clinical & Age, NIHSS & 1802 & Any & SHT & Yes \\
\hline & Imaging & ASPECTS, HMCA sign & & & & \\
\hline & Laboratory & Glucose & & & & \\
\hline $\begin{array}{l}\text { SITS-SICH } \\
{[7]}\end{array}$ & Clinical & $\begin{array}{l}\text { Age, antiplatelet medication, hypertension, NIHSS, stroke onset to } \\
\text { treatment time, SBP, weight }\end{array}$ & 31,627 & Any & SHT & Yes \\
\hline & Laboratory & Glucose & & & & \\
\hline $\begin{array}{l}\text { SPAN-100 } \\
{[33]}\end{array}$ & Clinical & Age, NIHSS & 624 & Any & Any HT & Regardless \\
\hline
\end{tabular}

Note: ${ }^{\mathrm{a}}$-year risk for major bleeding (intracranial, hospitalization, hemoglobin decrease $>2 \mathrm{~g} / \mathrm{L}$, and/or transfusion) in a cohort of real-world patients with AF

Table 14 AUC Comparison Between the HTI and Alternative Scores $(V C, n=248)$

\begin{tabular}{llll}
\hline Score & AUC $(95 \% \mathrm{NB} \mathrm{Cl})$ & $X^{2}(1)$ & $p$-Value \\
\hline HTI & $0.83(0.78-0.88)$ & - & - \\
Cucchiara & $0.72(0.67-0.77)$ & 31.6 & $<0.001$ \\
GRASPS & $0.80(0.75-0.84)$ & 10.98 & $<0.001$ \\
HAS-BLED & $0.53(0.47-0.59)$ & 86.47 & $<0.001$ \\
HAT & $0.82(0.77-0.88)$ & 4.34 & 0.037 \\
HeRS $^{\text {a }}$ & $0.81(0.75-0.86)$ & 4.11 & 0.043 \\
iSCore & $0.83(0.79-0.87)$ & 2.93 & 0.087 \\
SEDAN & $0.82(0.76-0.87)$ & 11.59 & $<0.001$ \\
SITS-SICH & $0.72(0.66-0.78)$ & 25.06 & $<0.001$ \\
SPAN-100 & $0.59(0.53-0.65)$ & 111.26 & $<0.001$ \\
\hline
\end{tabular}

Note: ${ }^{a}$ Infarct volume was calculated on follow-up CT scans $(\geq 12 \mathrm{~h}$ after the initial imaging) by using the $A B C / 2$ formula. ${ }^{b}$ For patients, who were not eligible for IV rtPA, stroke onset to treatment time was considered as stroke onset to admission time from the analysis due to a small number of observations. Although some clinical and imaging data were collected prospectively, the research was retrospective in nature. As a result, we were not blinded to the outcome. The study was also confined to a single clinical center; to cope with that bias, we used bootstrapping. Finally, prospective multicenter external validation would be desirable.

\section{Conclusions}

The HTI is a four-item tool composed of ASPECTS, NIHSS, HMCA sign, and presence of AF on ECG at admission. The total score ranges from zero to eight. The higher the score, the more likely HT can occur. Knowing probability of any HT in advance could exert a significant influence on decision making to reinstitute anticoagulation in AIS patients with AF. It is a simple yet reliable instrument to predict any HT within 2 weeks after onset of AIS in the MCA territory regardless of the use of IV rtPA. 


\section{Abbreviations}

AF: Atrial fibrillation; AHT: Asymptomatic hemorrhagic transformation; AIS: Acute ischemic stroke; ALT: Alanine transaminase; APTT: Activated partial thromboplastin time; ASPECTS: Alberta Stroke Program Early CT score; AST: Aspartate transaminase; AUC: Area under the ROC curve; BCa: Biascorrected and accelerated (adjusted for ties); BLR: Binary logistic regression; CFA: Confirmatory factor analysis; Cl: Confidence interval; CT: Computed tomography; DBP: Diastolic blood pressure; DC: Derivation cohort; DWI: Diffusion-weighted imaging; ECG: Electrocardiogram; EFA: Exploratory factor analysis; FMI: Fraction of missing information; HI-1: Hemorrhagic infarction type 1; HI-2: Hemorrhagic infarction type 2; HMCA: Hyperdense middle cerebral artery; HR: Heart rate; HT: Hemorrhagic transformation; HTI: Hemorrhagic transformation index; ICC: Intraclass correlation coefficient; ICR: Internal consistency reliability; INR: International normalized ratio; IQR: Interquartile range; IV rtPA: Intravenous recombinant tissue plasminogen activator; KDE: Kernel density estimate; LOWESS: Locally weighted scatterplot smoothing; LVEF: Left ventricular ejection fraction (echocardiography, Simpson method); MCA: Middle cerebral artery; MCMC: Markov chain Monte Carlo; MI: Multiple imputation; MRI: Magnetic resonance imaging; NB: Normal-based; NIHSS: National Institutes of Health Stroke Scale; OR: Odds ratio; PCF: Principal component factor; PF: Principal factor; $\mathrm{PH}-1$ : Parenchymal hematoma type 1; PH-2: Parenchymal hematoma type 2; PP: Predicted probability; PT: Prothrombin time; RBC: Red blood cells; RE: Relative efficiency; RIV: Relative increase in variance; ROC: Receiver operating characteristic; RRR: Relative risk ratio; SBP: Systolic blood pressure; SE: Standard error; SHT: Symptomatic hemorrhagic transformation; TIA: Transient ischemic attack; VC: Validation cohort; WBC: White blood cells

\section{Acknowledgements}

Not applicable.

\section{Funding}

No funding was received.

\section{Availability of data and materials}

The datasets used and/or analyzed during the current study are available from the corresponding author on reasonable request.

\section{Authors' contributions}

M.N.K. was involved in the design, data collection, analysis and interpretation, and reporting of this project. D.R.K. and M.M.I. helped with the design, data collection, data analysis, and revision of the manuscript. All authors have read and approved the final manuscript for publication.

\section{Ethics approval and consent to participate}

This study was approved by the Local Ethics Committee of the Kazan State Medical University, Kazan, Russia. Informed consent was not required since the study was observational and retrospective in nature.

\section{Consent for publication}

Not applicable.

\section{Competing interests}

The authors declare that they have no competing interests.

\section{Publisher's Note}

Springer Nature remains neutral with regard to jurisdictional claims in published maps and institutional affiliations.

\section{Author details}

'Department of Neurology and Neurosurgery for Postgraduate Training, Kazan State Medical University, Kazan, Russia. ${ }^{2}$ Department of Neurology, Interregional Clinical Diagnostic Center, 12A Karbyshev St, Kazan 420101, Russia. ${ }^{3}$ Department of Radiology, Interregional Clinical Diagnostic Center, Kazan, Russia.
Received: 4 July 2017 Accepted: 30 August 2017

Published online: 07 September 2017

\section{References}

1. Lei C, Wu B, Liu M, Chen Y. Asymptomatic hemorrhagic transformation after acute ischemic stroke: is it clinically innocuous? J Stroke Cerebrovasc Dis. 2014;23:2767-72.

2. Sussman ES, Connolly ES Jr. Hemorrhagic transformation: a review of the rate of hemorrhage in the major clinical trials of acute ischemic stroke. Front Neurol. 2013;4:69.

3. Zhang J, Yang Y, Sun H, Xing Y. Hemorrhagic transformation after cerebral infarction: current concepts and challenges. Ann Transl Med. 2014;2:81.

4. Quain DA, Parsons MW, Loudfoot AR, Spratt NJ, Evans MK, Russell ML, et al. Improving access to acute stroke therapies: a controlled trial of organised pre-hospital and emergency care. Med J Aust. 2008;189:429-33.

5. Lou M, Safdar A, Mehdiratta M, Kumar S, Schlaug G, Caplan L, et al. The HAT score: a simple grading scale for predicting hemorrhage after thrombolysis. Neurology. 2008;71:1417-23.

6. Cucchiara B, Tanne D, Levine SR, Demchuk AM, Kasner S. A risk score to predict intracranial hemorrhage after recombinant tissue plasminogen activator for acute ischemic stroke. J Stroke Cerebrovasc Dis. 2008;17:331-3.

7. Mazya M, Egido JA, Ford GA, Lees KR, Mikulik R, Toni D, et al. Predicting the risk of symptomatic intracerebral hemorrhage in ischemic stroke treated with intravenous alteplase: Safe Implementation of Treatments in Stroke (SITS) symptomatic intracerebral hemorrhage risk score. Stroke 2012;43: 1524-31.

8. Strbian D, Engelter S, Michel P, Meretoja A, Sekoranja L, Ahlhelm FJ, et al. Symptomatic intracranial hemorrhage after stroke thrombolysis: the SEDAN score. Ann Neurol. 2012;71:634-41.

9. Menon BK, Saver JL, Prabhakaran S, Reeves M, Liang L, Olson DM, et al. Risk score for intracranial hemorrhage in patients with acute ischemic stroke treated with intravenous tissue-type plasminogen activator. Stroke. 2012;43:2293-9.

10. Heidbuchel $H$, Verhamme $P$, Alings M, Antz M, Diener HC, Hacke W, et al. Updated European Heart Rhythm Association Practical Guide on the use of non-vitamin $\mathrm{K}$ antagonist anticoagulants in patients with non-valvular atrial fibrillation. Europace. 2015;17:1467-507.

11. Koo CK, Teasdale E, Muir KW. What constitutes a true hyperdense middle cerebral artery sign? Cerebrovasc Dis. 2000;10:419-23.

12. National Institute of Neurological Disorders and Stroke rt-PA Stroke Study Group. Tissue plasminogen activator for acute ischemic stroke. N Engl J Med. 1995;333:1581-7.

13. Fiorelli M, Bastianello S, von Kummer R, del Zoppo GJ, Larrue V, Lesaffre E, et al. Hemorrhagic transformation within 36 hours of a cerebral infarct: relationships with early clinical deterioration and 3-month outcome in the European Cooperative Acute Stroke Study I (ECASS I) cohort. Stroke. 1999; 30:2280-4.

14. Gadermann AM, Guhn M, Bruno DZ. Estimating ordinal reliability for Likerttype and ordinal item response data: a conceptual, empirical, and practical guide. Practical Assessment, Research \& Evaluation. 2012;17:3. http:// pareonline.net/getvn.asp? $v=17 \& n=3$

15. Trizano-Hermosilla I, Alvarado JM. Best alternatives to Cronbach's alpha reliability in realistic conditions: congeneric and asymmetrical measurements. Front Psychol. 2016;7:769.

16. Green $S B$, Yang Y. Reliability of summed item scores using structural equation modeling: an alternative to coefficient alpha. Psychometrika. 2009;74:155-67.

17. DeLong ER, DeLong DM, Clarke-Pearson DL. Comparing the areas under two or more correlated receiver operating characteristic curves: a nonparametric approach. Biometrics. 1988;44:837-45.

18. Neumann-Haefelin T, Hoelig S, Berkefeld J, Fiehler J, Gass A, Humpich M, et al. Leukoaraiosis is a risk factor for symptomatic intracerebral hemorrhage after thrombolysis for acute stroke. Stroke. 2006;37:2463-6.

19. Marsh EB, Llinas RH, Schneider AL, Hillis AE, Lawrence E, Dziedzic P, et al. Predicting hemorrhagic transformation of acute ischemic stroke: prospective validation of the HeRS score. Medicine (Baltimore). 2016;95:e2430.

20. Tan S, Wang D, Liu M, Zhang S, Wu B, Liu B. Frequency and predictors of spontaneous hemorrhagic transformation in ischemic stroke and its association with prognosis. J Neurol. 2014;261:905-12.

21. Zou M, Churilov L, He A, Campbell B, Davis SM, Yan B. Hyperdense middle cerebral artery sign is associated with increased risk of hemorrhagic transformation after intravenous thrombolysis for patients with acute ischaemic stroke. J Clin Neurosci. 2013;20:984-7. 
22. Terruso V, D'Amelio M, Di Benedetto N, Lupo I, Saia V, Famoso G, et al. Frequency and determinants for hemorrhagic transformation of cerebral infarction. Neuroepidemiology. 2009;33:261-5.

23. Paciaroni M, Agnelli G, Corea F, Ageno W, Alberti A, Lanari A, et al. Early hemorrhagic transformation of brain infarction: rate, predictive factors, and influence on clinical outcome: results of a prospective multicenter study. Stroke. 2008:39:2249-56

24. Pundik S, McWilliams-Dunnigan $\mathrm{L}$, Blackham $\mathrm{KL}$, Kirchner $\mathrm{HL}$, Sundararajan $\mathrm{S}$, Sunshine $J$, et al. Older age does not increase risk of hemorrhagic complications after intravenous and/or intra-arterial thrombolysis for acute stroke. J Stroke Cerebrovasc Dis. 2008;17:266-72.

25. Demchuk AM, Khan F, Hill MD, Barber PA, Silver B, Patel S, et al. Importance of leukoaraiosis on $\mathrm{CT}$ for tissue plasminogen activator decision making: evaluation of the NINDS rt-PA stroke study. Cerebrovasc Dis. 2008;26(2):120-5.

26. Nardi K, Leys D, Eusebi $P$, Cordonnier C, Gautier S, Hénon H, et al. Influence of lipid profiles on the risk of hemorrhagic transformation after ischemic stroke: systematic review. Cerebrovasc Dis Extra. 2011;1:130-41.

27. Kaesmacher J, Kaesmacher M, Maegerlein C, Zimmer C, Gersing AS, Wunderlich S, et al. Hemorrhagic transformations after thrombectomy: risk factors and clinical relevance. Cerebrovasc Dis. 2017:43:294-304.

28. Sandset EC, Berge E, Kjeldsen SE, Julius S, Holzhauer B, Krarup LH, et al. Heart rate as a predictor of stroke in high-risk, hypertensive patients with previous stroke or transient ischemic attack. J Stroke Cerebrovasc Dis. 2014; 23:2814-8.

29. Chen $\mathrm{CH}$, Huang PW, Tang SC, Shieh JS, Lai DM, Wu AY, et al. Complexity of heart rate variability can predict stroke-in-evolution in acute ischemic stroke patients. Sci Rep. 2015;5:17552.

30. Tatlisumak T, Fisher M. Hematologic disorders associated with ischemic stroke. J Neurol Sci. 1996;140:1-11.

31. Marsh EB, Llinas RH, Hillis AE, Gottesman RF. Hemorrhagic transformation in patients with acute ischaemic stroke and an indication for anticoagulation. Eur J Neurol. 2013:20:962-7.

32. Saposnik G, Fang J, Kapral MK, Tu JV, Mamdani M, Austin P, et al. The iScore predicts effectiveness of thrombolytic therapy for acute ischemic stroke. Stroke. 2012;43:1315-22.

33. Saposnik G, Guzik AK, Reeves M, Ovbiagele B, Johnston SC. Stroke prognostication using age and NIH Stroke Scale: SPAN-100. Neurology. 2013;80:21-8.

34. Yong AG, Pearce S. A Beginner's guide to factor analysis: focusing on exploratory factor analysis. Tutor Quant Methods Psychol. 2013:9:79-94.

35. Asuzu D, Nystrom K, Amin H, Schindler J, Wira C, Greer D, et al. Comparison of 8 scores for predicting symptomatic intracerebral hemorrhage after IV thrombolysis. Neurocrit Care. 2015;22:229-33.

36. Sung SF, Chen SC, Lin HJ, Chen YW, Tseng MC, Chen CH. Comparison of risk-scoring systems in predicting symptomatic intracerebral hemorrhage after intravenous thrombolysis. Stroke. 2013;44:1561-6.

37. Demeestere J, Garcia-Esperon C, Garcia-Bermejo P, Ombelet F, McElduff P, Bivard A, et al. Evaluation of hyperacute infarct volume using ASPECTS and brain CT perfusion core volume. Neurology. 2017;88:2248-53.

38. González RG, Schaefer PW, Buonanno FS, Schwamm LH, Budzik RF, Rordorf G, et al. Diffusion-weighted MR imaging: diagnostic accuracy in patients imaged within 6 hours of stroke symptom onset. Radiology. 1999;210:155-62.

39. Schröder J, Cheng B, Ebinger M, Köhrmann M, Wu O, Kang DW, et al. Validity of acute stroke lesion volume estimation by diffusion-weighted imaging-Alberta Stroke Program Early Computed Tomographic Score depends on lesion location in 496 patients with middle cerebral artery stroke. Stroke. 2014:45:3583-8.

40. Merwick Á, Werring D. Posterior circulation ischaemic stroke. BMJ. 2014;348: g3175.

41. Sarikaya H, Arnold M, Engelter ST, Lyrer PA, Mattle HP, Georgiadis D, et al. Outcomes of intravenous thrombolysis in posterior versus anterior circulation stroke. Stroke. 2011;42:2498-502.

42. Libman RB, Kwiatkowski TG, Hansen MD, Clarke WR, Woolson RF, Adams HP. Differences between anterior and posterior circulation stroke in TOAST. Cerebrovasc Dis. 2001;11:311-6.

43. Tong X, Liao X, Pan Y, Cao Y, Wang C, Liu L, et al. Intravenous thrombolysis is more safe and effective for posterior circulation stroke: data from the Thrombolysis Implementation and Monitor of Acute Ischemic Stroke in China (TIMS-China). Medicine (Baltimore). 2016;95:e3848.
44. Oppenheim C, Stanescu R, Dormont D, Crozier S, Marro B, Samson Y, et al False-negative diffusion-weighted MR findings in acute ischemic stroke. AJNR Am J Neuroradiol. 2000;21:1434-40.

45. Puetz V, Sylaja PN, Coutts SB, Hill MD, Dzialowski I, Mueller P, et al. Extent of hypoattenuation on $C T$ angiography source images predicts functional outcome in patients with basilar artery occlusion. Stroke. 2008;39:2485-90.

46. Pisters R, Lane DA, Nieuwlaat R, de Vos CB, Crijns HJ, Lip GY. A novel userfriendly score (HAS-BLED) to assess 1-year risk of major bleeding in patients with atrial fibrillation: the Euro Heart Survey. Chest. 2010;138:1093-100.

\section{Submit your next manuscript to BioMed Central and we will help you at every step:}

- We accept pre-submission inquiries

- Our selector tool helps you to find the most relevant journal

- We provide round the clock customer support

- Convenient online submission

- Thorough peer review

- Inclusion in PubMed and all major indexing services

- Maximum visibility for your research

Submit your manuscript at www.biomedcentral.com/submit
Biomed Central 